CONSCIOUSNESS, RESISTANCE, AND PRAXIS:

\title{
COUNTER-NARRATIVES OF TRANSFORMATIVE LEADERS OF COLOR
}

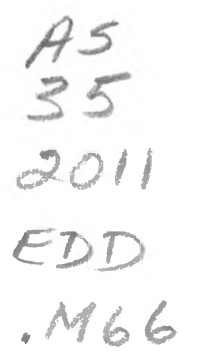

A dissertation submitted to the faculty of

San Francisco State University

in partial fulfillment of
the requirements for
the degree

Doctor of Education

in

Educational Leadership

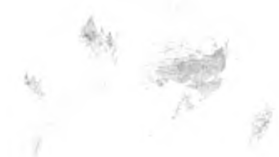

by

Alexis S. Montevirgen

San Francisco, California

January 2011 
Copyright by

Alexis S. Montevirgen

2011 


\section{CERTIFICATION OF APPROVAL}

I certify that I have read Consciousness, Resistance, and Praxis: Counter-Narratives of Transformative Leaders of Color by Alexis S. Montevirgen and that in my opinion this work meets the criteria for approving a dissertation submitted in partial fulfillment of the requirements for the degree: Doctor of Education in Educational Leadership at San Francisco State University.

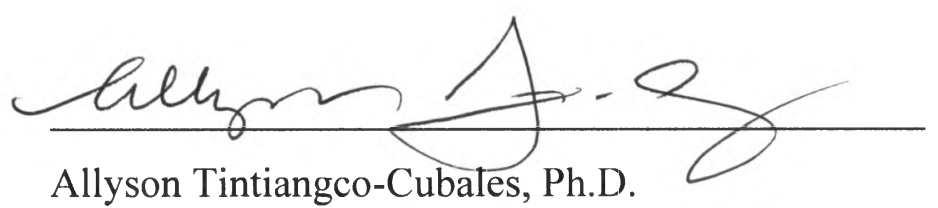

Associate Professor, College of Ethnic Studies

San Francisco State University

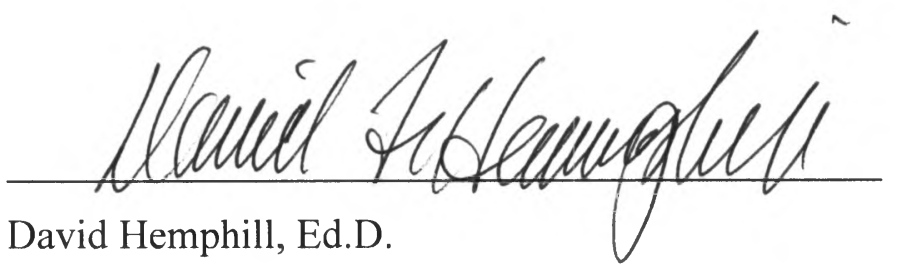

Associate Dean and Professor, College of Education

San Francisco State University

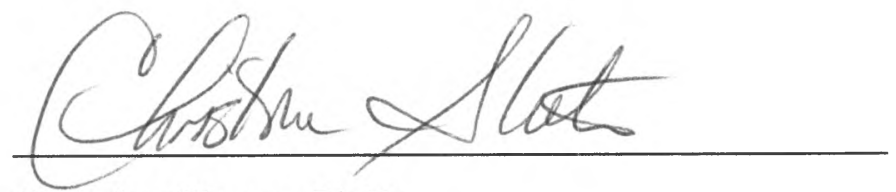

Christine Sleeter, Ph.D.

Professor Emerita, College of Professional Studies

California State University Monterey Bay 


\title{
CONSCIOUSNESS, RESISTANCE, AND PRAXIS: COUNTER-NARRATIVES OF TRANSFORMATIVE LEADERS OF COLOR
}

\author{
Alexis S. Montevirgen \\ San Francisco, California
}

2011

Using counter-narrative to frame the qualitative methodology, this dissertation shifts the paradigm of educational leadership by situating the experiences of transformative leaders of color as part of the dominant discourse. A theoretical framework drawing from Critical Race Theory (CRT), decolonization, and Freirean critical pedagogy is used to present a model for transformative educational leadership pedagogy which focuses on the values of consciousness, resistance, and praxis in order to directly challenge and counter more traditional leadership values of authority, power, and control. The dissertation provides a set of four recommendations which can be implemented to support and further the development of transformative leaders of color.

I certify that the Abstract is a correct representation of the content of this dissertation.

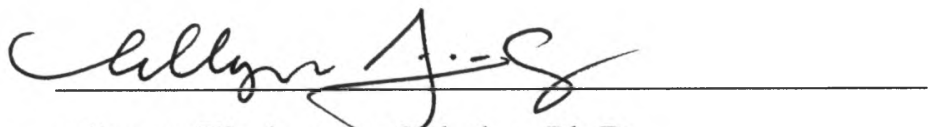

Allyson Tintiangco-Cubales, Ph.D.

Chair, Dissertation Committee
December 15,2010

Date 


\section{ACKNOWLEDGEMENT}

First and foremost, I would like to thank my parents, Crispulo and Nancita Montevirgen, for instilling in me the values which have allowed me to become the individual who I am today. I would also like to thank all of the family, friends, mentors, mentees, colleagues, and students who have inspired and encouraged me throughout this entire journey.

To the transformative leaders of color who shared their stories as part of this dissertation, thank you. I hope that I have been able to convey your counter-narratives with the level of respect and authenticity that they rightfully deserve.

To my advisor and dissertation chair, Dr. Allyson Tintiangco-Cubales, thank you for believing in me and continuing to challenge and push me throughout the dissertation process. Your guidance and support carried me through and gave me the strength to persevere all the way until the final revision.

To Dr. David Hemphill and Dr. Christine Sleeter, thank you for your encouragement, support, feedback, and patience. I am truly honored to have had both of you on my dissertation committee as content experts who understood and supported my research.

To Cohort 2007, together we developed a community of scholars which I will value long after we have all finished the program. As members of the first cohort, we endured various program adjustments and surprises along the way, but we did it. Congratulations! 


\section{TABLE OF CONTENTS}

LIST OF TABLES.

$\mathrm{X}$

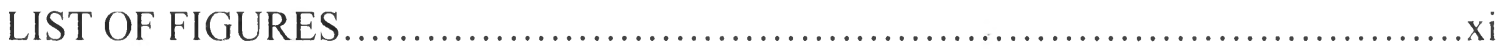

LIST OF APPENDICES ..............................................................

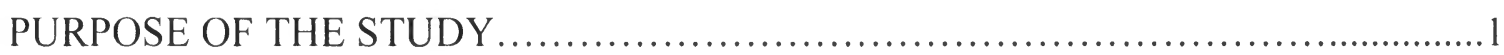

Statement of the Problem......................................................4

Counter-Narrative as a Methodological Tool...................................6

Master-Narrative..................................................... 7

Counter-Narrative................................................ 8

Master-Narrative vs. Counter-Narrative...................................... 10

Conclusion............................................................ 11

LITERATURE REVIEW ................................................... 12

Community College Organizational Culture and Change...................... 13

Current Research on the Experiences of Administrators of Color........16

Educational Leadership Theory and Research.............................. 19

Servant and Moral Leadership....................................20

Transformational Leadership......................................21

Distributed Leadership...........................................22 
Transformative Leadership.....................................23

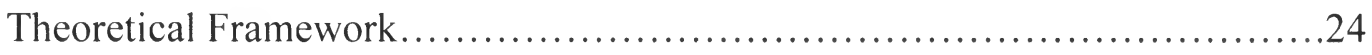

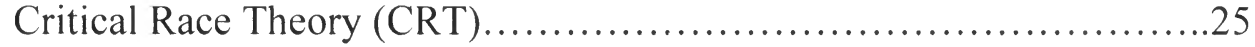

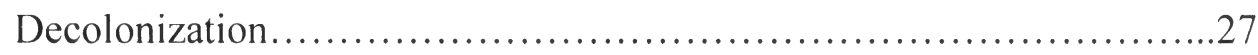

Freirean Critical Pedagogy.........................................29

Conclusion.................................................................. 31

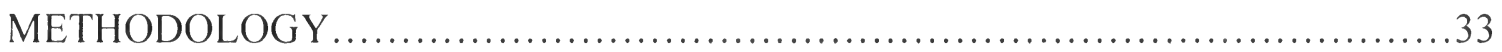

Counter-Storytelling and Counter-Narrative.................................33

Consciousness, Resistance, and Praxis: An Identity Development

Model for Transformative Leaders of Color....................................... 36

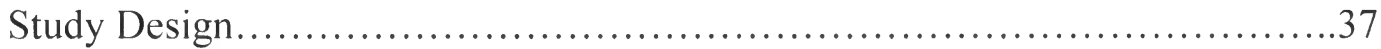

Research Questions.................................................... 37

Overview of Study Procedures....................................... 38

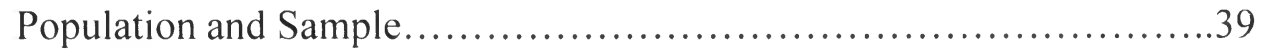

Data Collection.................................................42

Data Analysis Procedures..........................................43

Role of the Researcher................................................43

Strengths and Limitations of the Research................................44

CONSCIOUSNESS: THE DEVELOPMENT OF TRANSFORMATIVE

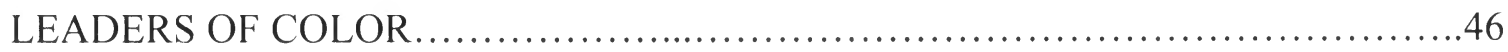

Awakening....................................................... 47

Liliana Rojas...............................................48 
Acknowledgement..................................................... 50

Tracey Vu-Kwon........................................................

Sherry Singleton................................................... 56

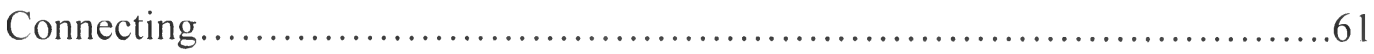

Miguel Suarez..........................................................62

Matthew Pearson.....................................................66

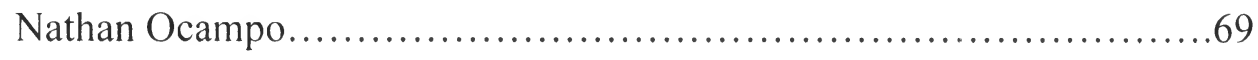

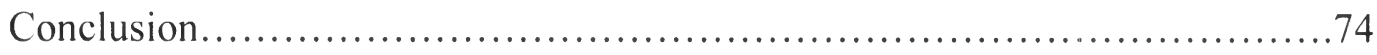

RESISTANCE: TRANSFORMATIVE LEADERS OF COLOR REFLECT ..............75

Counter-Hegemonic Resistance.........................................76

Karen Hamamoto..................................................... 77

Andres Rodriguez................................................ 79

Fred Chieu ...................................................... 82

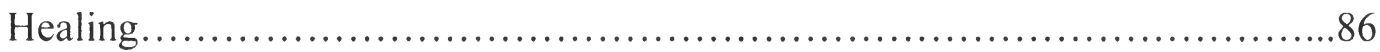

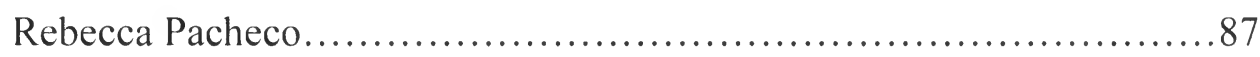

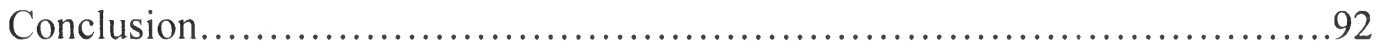

PRAXIS: DEVELOPING A TRANSFORMATIVE EDUCATIONAL

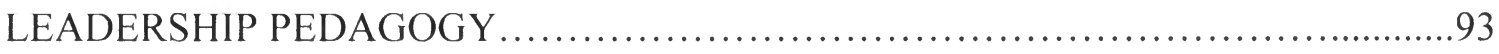

Humanization.............................................................. 93

Rochelle Simpson................................................ 94

Humility ........................................................... 101

Liliana Revisited............................................... 101 
Nathan Revisited.................................................. 102

Karen Revisited............................................... 103

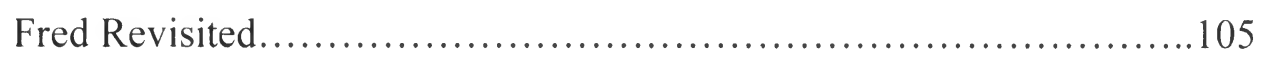

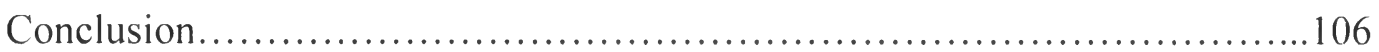

DISCUSSION AND RECOMMENDATIONS .................................. 108

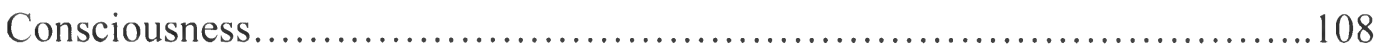

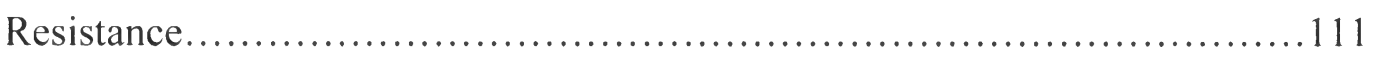

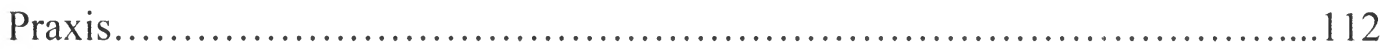

Recommendations to Support the Development of Consciousness,

Resistance, and Praxis in Transformative Leaders of Color...........................113

Recommendation 1 .................................................. 114

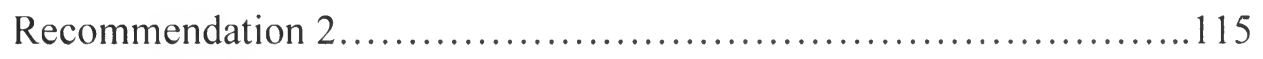

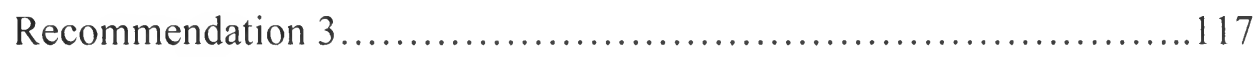

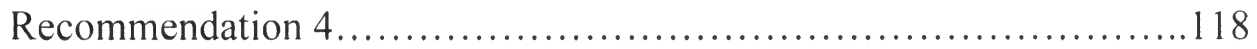

Implications and Possibilities for Future Research............................ 120

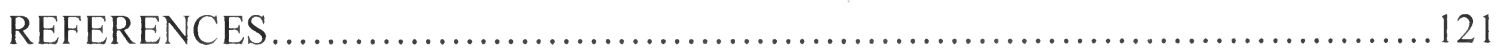

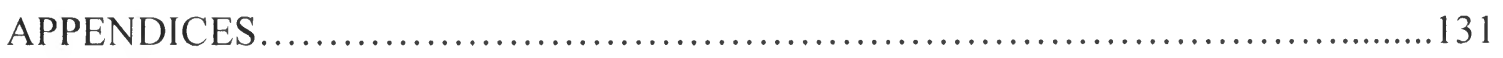

Appendix A: Semi-Structured Interview Protocol............................131

Appendix B: Informed Consent Form.....................................132 


\section{LIST OF TABLES}

Table Page

1. Participants by College/District (Pseudonyms)................................40

2. Participants by Position/Area/Race/Ethnicity/Gender/LGBT Identification........41 


\section{LIST OF FIGURES}

Figure

Page

1. Cognitive Map............................................................... 37 


\section{LIST OF APPENDICES}

Appendix

Page

A. Semi-Structured Interview Protocol....................................... 131

B. Informed Consent Form................................................. 132 


\section{PURPOSE OF THE STUDY}

As a community college administrator of color, there have been numerous instances throughout my career where I have felt very lonely, conflicted, and burnt out. Yet both as a professional and as a doctoral student in educational leadership, I struggle to find literature which acknowledges and validates these personal experiences. Even within the literature that I found discussing emotional labor (Blake, 2007; Dillon \& Tanner, 1995; Wong, 2007) and third shift (Bolton, 2000), there still seemed to be an acceptance that the experiences of administrators of color were "different" or "unusual" in relationship to the normative experiences of leaders from the dominant group. It continues to feel as if even within the discourse on educational leadership pedagogy, a deficit-minded approach is being used to understand the leadership identity development and experiences of transformative leaders of color.

This dissertation wishes to shift the paradigm of educational leadership pedagogy and situate the experiences of transformative leaders of color as part of the dominant discourse. In using the term educational leadership pedagogy throughout this dissertation, I focus on the process of how leadership values are developed, learned, and taught from one leader to the next, instead of simply accepting educational leadership theory as defined and prescribed through traditional leadership models.

Using counter-narrative and counter-storytelling (Delgado, 1989 \& 1993; Neilson \& Suyemoto, 2009; Solorzano \& Yosso, 2001) to frame the qualitative methodology, this 
dissertation provides a unique glimpse into the personal leadership experiences of twelve transformative leaders of color - that of myself and the eleven other community college administrators who participated in this study.

Perhaps one of the most critical voices calling for a more transformative discourse in educational leadership pedagogy is Jane Wilkinson, who states that "in an increasingly emancipator world, the largely masculinist, white norms from which most accounts of leadership derive, lack sufficient explanatory power for educational systems" (2008, p.101). Wilkinson goes on to state that, "One of the potential dangers of emerging research for diversity and educational leadership is a slippage into an apolitical and instrumentalist focus upon diversity as a form of management containment of individuals" (p.102). Wilkinson's statements echo my earlier argument that current research on educational leadership still seems to be taking a deficit-minded approach to the experiences of transformative leaders of color. According to Wilkinson, without a move towards a more transformative discourse in educational leadership research, issues of diversity and multiculturalism will continue to be presented as marginal, using the white male experience as a central point of reference and thus further alienating minority communities from mainstream leadership values.

Similar to Wilkinson, Jill Blackmore (2006a) discusses the need to deconstruct diversity discourses in the field of educational management and leadership by arguing that neoliberal manegerialist discourses have led to the belief that social action is fully explicable through theories of maximizing self-interest, a very individualistic view of 
leadership as opposed to the more collaborative view which transformative leaders subscribe to. As a result, Blackmore believes that what has occurred is a traditional view of learning and leadership as an individual accomplishment and not as a collective practice. For example, according to Blackmore, many aspirant women leaders still consider representations of leadership, both visual and textual, as homogenized, monocultural, and often masculinist, thus discouraging female, minority and indigenous applicants. Again, as long as the white male experience continues to serve as a central point of reference and there are no attempts to shift the discourse towards being more inclusive of the experiences of women and people of color, administrators who come from these marginalized communities will continue to feel discouraged and disenfranchised, even as more and more gain entry into leadership positions. In another article, Blackmore (2006b) utilized a feminist history and feminist lens to describe social justice and the study and practice of leadership in education. Blackmore argued that "Educational administration as a field can no longer ignore the material, social, and cultural conditions under which students learn, teachers teach, and leaders lead" (p.196-197). What this means for educational leadership in particular, is the need to shift the entire paradigm of leadership to be more inclusive of how the material, social and cultural conditions impact the experiences and leadership identities of individual leaders.

This dissertation extends the work of Wilkinson and Blackmore by focusing specifically on the leadership experiences of transformative leaders of color and giving 
value, acknowledgement, and - as one of the research participants themselves stated honor to their experiences. In the next chapter I will begin by providing a review of literature on the organizational culture and challenges facing community colleges and institutions of higher education. I will then present a general review of literature on educational leadership theory and practice - from its early ties to corporate business models of organizational theory to its more recent trajectory towards servant, transformational, distributed, and transformative forms of leadership practices. The final section of the literature review will bring together the theoretical frameworks of Critical Race Theory (CRT), decolonization, and Freirean critical pedagogy to frame an identity development model for transformative educational leadership pedagogy.

Statement of the Problem

The overarching research question which guides this study is: How can transformative leadership values of consciousness, resistance, and praxis be used instead of more traditional leadership values of authority, power and control to better understand the leadership experiences of community college administrators of color?

This dissertation argues that a continued analysis of the leadership experiences of community college administrators of color using traditional leadership values of authority, power, and control would only perpetuate the marginalization experienced by these leaders. By focusing the analysis on the counter-narratives and introducing transformative values of consciousness, resistance and praxis, a new lens can be used to examine the leadership experiences of transformative leaders of color. More specifically, 
this dissertation will examine how educational leaders develop each of these three transformative leadership values as part of their overall leadership identity development process. By focusing on how each of the administrators of color develop consciousness, resistance, and praxis, this dissertation will conclude with a list of summary recommendations which can be used to support the leadership development process for transformative leaders of color.

Transformative educational leaders are those who actively engage in selfreflection; critically and systematically analyzing schools and then confronting inequities regarding race, class, gender, language, ability, and/or sexual orientation as they work towards the social transformation of schooling (Brown, 2004; Cambron-McCabe \& McCarthy, 2005; Cooper, 2009; Dantley, 2003; Lopez, 2003; Marshall \& Oliva, 2006; Quantz, Rogers, \& Dantley, 1991; Theoharis, 2007).

Using the experiences of community college administrators of color and their personal counter-narratives, I will present in chapter three an identity development model for transformative leaders which focus on the values of consciousness, resistance, and praxis. I ground these three values of consciousness, resistance and praxis by drawing from the theoretical frameworks of Critical Race Theory (Buenavista, Jayakumar, \& Misa-Escalante, 2009; Delgado, 1995; Ladson-Billings \& Tate, 1995; Smith-Maddox \& Solorzano, 2002; Solorzano, 1998; Solorzano \& Yosso, 2001; Teranishi, et al., 2009), decolonization (Fanon, 1963; Memmi, 1965 \& 2006; Ngugi wa Thiong’o, 1986; Smith, 1999; Strobel, 2001; Tejeda, Espinoza, \& Gutierrez, 2003), and Freirean critical 
pedagogy (Friere, 1970). Each of these three theoretical frameworks will be expanded upon in the next chapter.

While this dissertation wishes to shift the discourse to be more acknowledging of transformative educational leadership pedagogy, it does not wish to argue a need to completely dismiss the traditional leadership values of authority, power, and control in place of consciousness, resistance and praxis. In fact, as it will emerge in many of the counter-narratives, a key challenge for transformative leaders of color is how to continually navigate and maneuver between both traditional leadership expectations and their transformative leadership identity. The traditional leadership values of authority, power, and control are still leadership realities that transformative leaders of color will find themselves needing to operate under.

\section{Counter-Narrative as a Methodological Tool}

While the use of counter-narrative as a methodological tool will be described more thoroughly in chapter three, I end this chapter by providing an example of the difference between what I distinguish as the master-narrative and the counter-narrative for leaders and administrators in higher education. In terms of the master-narrative, the focus will noticeably be on position, rank, educational level, professional qualifications and other attributes related to authority, power, and control which are often used to describe traditional educational leadership pedagogy. The counter-narrative will be quite different and will focus instead on the personal experiences and life stories related to the transformative values of consciousness, resistance, and praxis which more effectively 
describe the educational leadership pedagogy and leadership identity development process for transformative leaders of color.

Master-Narrative

The author of this dissertation is a doctoral student in the Ed.D. program in Educational Leadership at San Francisco State University. He received his M.S.Ed. in Education, Culture and Society from the University of Pennsylvania's Graduate School of Education and his master's research was on heritage language learning and the construction of cultural identity among second generation Filipino American undergraduate students. He completed his undergraduate degree from the University of California, San Diego.

Professionally, the author is currently the Dean of Student Support Services at College of Alameda. Prior to his current position, he has served as Director of Student Life at Evergreen Valley College, as Associate Director for Multicultural Programs at California State University San Marcos, and as Coordinator for Student Organization Development and Special Programs at San Jose State University. In addition to his professional experience, he has also taught college-level courses in sociology, communication, and education.

In his current position at College of Alameda, the dean reports to the Vice President of Student Services and oversees the college's student services areas of financial aid, student activities, veteran's affairs, career center, outreach, and scholarships. The dean provides budgetary oversight and fiscal responsibilities for 
annual funding in excess of half a million dollars and supervises the work of classified supervisors/managers, classified staff, hourly staff, and hourly student workers.

\section{Counter-Narrative}

In his office hangs a painting which symbolizes his experience as a transformative leader of color. Alexis acquired the painting, an unsigned piece of student artwork during his first year working as a student affairs professional, and has kept it with him ever since. It is a painting of a man leading a group of fellow brown faces from the darkness. With his fist raised and a somber yet determined look on his face, the man stands at the foreground while the background is filled with what seems like an endless sea of people, equally somber in their expression and following behind the leader.

There have been several times when the sight of the painting has evoked strong emotions as Alexis reflects on how the painting serves as a constant reminder of the loneliness and isolation it sometimes feels to be a transformative leader of color. Lonely and isolating - feeling as if he is alone fighting for issues of equity and social justice within an educational system filled with leaders who cannot even understand or relate to his experience as an administrator of color. What makes it even more difficult for him is knowing that, similar to the painting, there is a sea of students of color who are counting on him to make changes to the educational system so that it is more responsive to the needs of students of color.

Born in the Philippines and brought to the United States by his immigrant parents at the very young age of seven months, Alexis self-identifies himself as a 1.95 generation 
Filipino American. Alexis explains his choice of self-identifying as 1.95 generation as a result of the fact that he does not see himself fitting into either of the definitions for a 1.5 generation immigrant - someone born outside of the United States who came to the country between the ages of 8-15 years old, or the definition for second generation - the first generation of children to be born in the United States from immigrant parents. Alexis' insistence on creating his own unique definition to describe himself is an example of the critical consciousness, resistance, and praxis of transformative leaders of color. Instead of simply allowing himself to be placed into pre-established categories, categories typically created by those from dominant groups to describe and further marginalize "others," he chooses to create his own definition to best describe his identity.

As the oldest of two children and having been raised in a working-class family, Alexis often reflects on how he believes that he was never able to fully experience his childhood and was instead forced to grow up and begin assuming adult responsibilities as a young child. From an early age, Alexis took on a leadership role within his family as he helped to watch over his younger brother while both of his parents had to work. Alexis also recalls how as early as the third or fourth grade, he would already be responsible for household responsibilities such as preparing the rice and getting dinner started so that it would be easier for his mom to finish cooking dinner when she and his dad would come home from work at the end of a long day. As Alexis looks back, he realizes that many of his first lessons in leadership were instilled in him through these early childhood experiences. 
Growing up in an immigrant family, Alexis was also brought up with traditional Filipino cultural values which placed a strong emphasis on humility and respect for elders. As a result, Alexis is not comfortable talking about himself and/or drawing personal attention when working in a group environment. He is also not the type of individual who is comfortable challenging and talking back to those who are older than him or hold higher leadership positions. These are two deeply rooted cultural values which Alexis has really had to negotiate and struggle with as he has taken on different leadership positions throughout his professional administrative career.

\section{Master-Narrative vs. Counter-Narrative}

Both the master-narrative and the counter-narrative were purposefully written in the third person. Despite this, I believe that the use of impersonal pronouns and titles/positions to refer to the subject in the master-narrative is already an example of the normative expectation in dominant research. The intentional use of my first name in the counter-narrative is one small example of how I am hoping to shift educational leadership discourse to become more personal and real. It is my belief that referring to individuals by first name throughout the counter-narrative makes it easier for the reader to connect and resonate with the experience being told. Counter-narrative also provides a sense of humanization which provides the reader with an added level of depth and substance to the character being presented and the experience being shared.

While the master-narrative contained important information about my educational background, work history, and the scope of my current leadership responsibilities, I hope 
that by presenting the counter-narrative I have been able to make a case for the importance of the counter-narrative as a way to obtain a fuller and more complete perspective into the transformative leadership identity development process for administrators of color. In chapters four, five and six, I present eleven additional counter-narratives to show how values of consciousness, resistance, and praxis influence the identity development process for transformative leaders of color.

\section{Conclusion}

In the final chapter of this dissertation, I will present an analysis and synthesis of emerging themes, provide recommendations, and discuss implications for future research. The findings from this dissertation provide a new model that can be used to acknowledge, validate, and recognize the leadership experiences of transformative leaders of color. This new model, focused on the transformative leadership values of consciousness, resistance, and praxis, should be used to design leadership development programs which will more adequately and more appropriately support the identity and leadership development processes for transformative leaders of color. 


\section{LITERATURE REVIEW}

I begin the review of the literature by focusing on community college organizational culture and change. It will be important to understand the community college context in order to effectively apply transformative leadership theories to the experiences of community college administrators. The review of community college literature will also identify a major gap in the current body of community college research resulting from an absence of theoretical and methodological approaches which are informed by the experiences of transformative leaders of color.

The second section of the literature review will focus on presenting a general overview of the literature on educational leadership theory and practice and its early connections to corporate business models of organizational theory (Collins, 200 l; Gardner, 1990; Senge, 1990). From there, I will begin to focus in on the field of educational leadership by examining literature on servant and moral leadership (Fullan, 2001; Purpel, 2004; Sergiovanni, 1992), transformational leadership (Bass, 1998; Burns, 1978; Yukl, 1999), distributed leadership (Elmore, 2000; Hall \& Hord, 2006), and transformative leadership (Cooper, 2009; Dantley, 2003; Shields, 2000 \& 2003; Shields \& Sayani, 2005).

The final section of the literature review provides the theoretical framework for

this dissertation by presenting Critical Race Theory, decolonization, and Freirean critical pedagogy as the main theoretical concepts which frame the values of consciousness, 
resistance, and praxis in the model for transformative educational leadership pedagogy that will be presented in chapter three.

\section{Community College Organizational Culture and Change}

In order to examine the experiences of community college administrators, it is important to first situate the context in which the administrators operate. This section provides a review of literature which focuses on the overall organizational culture of community colleges.

Critiquing the available literature on community college culture, Levin (1994) argued that community college change literature up until that time had mainly focused on how societal and economic changes influenced institutions rather than on how community colleges had changed and impacted society. In a follow-up study using interviews with over two hundred administrators, faculty, staff, students, and board members at six community colleges in the United States and Canada during 1996 and 1997, Levin (1998) examined how organizational change occurred in community colleges. Levin concluded that organizational change in the community college was conveyed through storytelling, through descriptions and explanations that organizational members gave to make sense not only of their organization but also of the relationship between the organization and its environment.

According to Levin, organizational change resulted from the interplay between 'external determinism' and 'internal control', between the perceptions and actions of the internal members of organizational identity and the structures and limitations placed on 
the institution by the external environment. Community colleges were therefore not static organizations, instead, they altered, changed their approaches, changed their programs, and existed within a fluid structure that coexisted in relationship with their environment.

With community colleges serving more and more of the nation's underserved and marginalized communities, it is important now more than ever that we have community college leaders who understand and are aware of the needs of these student groups. We must find ways to recruit, support, and develop transformative educational leaders to lead the social change efforts at our community colleges.

Using case studies of several community colleges, Rhoads and Valadez (1996) presented what they believed an ideal and democratic community college should look like. As part of their findings, the authors provided a set of principles which were meant to guide students, faculty, and administrators "concerned with restructuring more democratic and multicultural academic communities" (p.210). Four of the principles included: (a) the need for greater collaboration and more participatory management processes within community college leadership, (b) the need for community college officials to create opportunities for others to assume leadership, (c) the need for a culturally diverse faculty, staff, and student body participating in organizational decision making, and (d) the need for community colleges to embrace change as a way of life.

As the leaders and champions of organizational change efforts at their colleges, community college presidents face tremendous pressures and challenges as they lead 
their institutions through ongoing organizational change efforts. Organizational pressures and challenges facing community college administrators are far more complex than those of previous generations (Vaughan \& Weisman, 1998).

In examining the impact of presidential cognition on organizational change Eddy (2004) argued that it was important to understand the cognitive orientation that community college presidents employ as they make the decisions on how to lead their organizations. From 28 interviews, Eddy found two main themes: (a) leader cognition drove not only the choice of change goals, but also the strategies used to implement the goals, and (b) that there was a concept of ongoing learning and continual adjustment that took into account new experiences.

The findings from Eddy and Vaughn and Weisman are important because they consider not just the tangible skills and characteristics that administrators project as leaders of their institutions, but also the importance of internal cognition and selfawareness. This dissertation expands the literature in this area by documenting the importance of consciousness, resistance, and praxis as internal cognition and selfawareness processes for transformative educational leaders.

In a study conducted by Hull and Keim (2007) which examined the nature and status of community college leadership development programs, those surveyed identified a need to expand leadership development opportunities at their institutions. The study also indicated that those surveyed placed an importance on the role of mentoring in preparing community college administrators for leadership positions. An additional 
component to mentoring which this dissertation wishes to add to the current body of literature is the importance of culturally based mentoring programs and their specific contributions to the development and retention of transformative leaders of color.

Sampling more than 500 California community college administrators at the level of dean or higher and who represented four major ethnic/racial groups (African American, Asian/Pacific Islander, Caucasian, and Hispanic/Latino), Currie (1994) explored similarities and differences in leadership styles and preferences along ethnic/racial groups. While Currie's findings indicated that there was some slight internalization among African American and Hispanic/Latino administrators compared to their Caucasian counterparts regarding the extent to which one's own ethnicity/race played a role in how they were perceived and viewed by others, one of the major conclusions of the study focused on what the administrators held in common across ethnic/racial groups. Irrespective of one's ethnic/racial identification, the study found that senior community college administrators in California indicated a preference for a leadership style reflecting the highest level of participatory behavior. This preference supports the trajectory of educational leadership theory away from traditional authoritarian models towards more transformational and distributed forms of leadership. Current Research on the Experiences of Administrators of Color

Using in-depth interviews, transcripts, participant resumes, and researcher field notes, Mickles (2005) conducted a qualitative study of the experiences and perceptions of African American community college presidents in Virginia, North Carolina, and 
Maryland. Three major assertions emerged from Mickles’ study: (a) experiences, a strong support system, and mentoring can facilitate a path to a community college presidency; (b) there are issues and challenges based on racial background that tend to encourage or discourage minorities in educational leadership positions; and (c) there are undeniable factors and issues that limit or prevent minority entry into educational leadership positions.

To look at the issues and challenges facing Latino leadership in community colleges, Gutierrez, Castaneda, and Katsinas (2002) surveyed participants of the $7^{\text {th }}$ annual summer symposium of the National Community College Hispanic Council (NCCHC) in 2001. Of the 26 survey respondents, the authors determined that 16 held senior-level positions. Only results and comments from the senior-level administrators were analyzed and three themes emerged around the key experiences in the Latino administrator's career path which they felt prepared them for their current position: (a) quality mentoring experiences, (b) participation in leadership development programs of both a formal and informal nature, and (c) having a variety of experiences at differing levels of responsibility.

In her examination of the pathways to the presidency for women of color firsts, Turner (2007) presented biographical sketches of three women of color who were the first Mexican American, Native American, and Asian Pacific/Asian American women to become presidents of public, baccalaureate degree-granting colleges or universities. In her study, Turner discussed the following themes which emerged from her research: (a) 
the power or storytelling, (b) the important role of interpersonal connections, (c) the use of nontraditional leadership style to bring diverse communities together, (d) the importance of how the women of color firsts responded to initial challenges in setting the tone for the rest of their tenure, (e) the importance of visioning and ability to anticipate the future, and (f) the importance of individual and institutional match. Many of these similar themes will be visible in the counter-narratives that will be presented in chapters four, five, and six.

Using qualitative methods of semi-structured interviews and co-authored narratives of Asian women leaders in higher education, Ideta (1996) described an emergent theme among the Asian women leaders of the ability to become stronger and more determined in pursuit of goals as a result of being confronted by discriminating situations stemming from racism, classism, and sexism.

Even within the research on issues of racial inequities among the numbers of college administrators and presidents, Teranishi, et al. (2009) found that Asian Americans were simply left out in most of the studies. For Asian American leaders, the perceived presence of a glass ceiling which prevents them from reaching the highest levels of administration is another indication that culture and race does matter (Neilson \& Suyemoto, 2009). Chou (1992) described the glass ceiling for Asian American leaders as the result of two different cultural styles clashing and in conflict with each other. Even more troubling is the lack of Asian American graduate students working towards advanced degrees in educational leadership (Committee of 100, 2005; Ong, 2008). These 
studies conclude that improving professional development programs and career pipelines for prospective Asian American leaders in higher education can be aided by acknowledging the experiences and cultural realities that exist for Asian American as part of the normal discourse.

The common theme across the research on the experiences of administrators of color was what Mickles (2005) described as undeniable factors and issues related to culture and race which impact the leadership experiences of administrators of color. All of the studies articulated a need for theoretical and methodological approaches to research on educational leadership which acknowledge the impact of culture and race on the experiences of transformative leaders of color. This dissertation will advocate for the use of counter-narrative as one method which can be used to address that need.

\section{Educational Leadership Theory and Research}

Most of the theory and research on organizational leadership find their roots in corporate business management models. While there are some important lessons and overarching themes that can be learned from the corporate business world such as systems thinking (Senge, 1990), level five leadership (Collins, 2001), and key challenges facing management and leadership groups in general (Gardner, 1990), being a leader in the field of education is very different from being the leader of a private business or corporation. As a result, theory and research on educational leadership has adapted and developed various different leadership styles which are more applicable to the educational setting. 


\section{Servant and Moral Leadership}

In response to the more command and authoritative qualities valued in traditional leadership settings, Sergiovanni (1992) describes a form of leadership as stewardship that incorporates the concept of servant leadership developed by Greenleaf (1977). The importance of servant leadership, according to Sergiovanni, is in the fact that instead of maximizing self-interest and individual achievement, servant leadership shifts the focus on the leader needing to understand and address the needs of the community that they are serving.

Fullan (2001) further extends the idea of servant leadership by drawing a connection to moral purpose. According to Fullan (2003), the field of education is unique because it includes a moral purpose and educational leaders have a moral responsibility to ensure that all students and teachers are successful so that the achievement gap between high and low performers is reduced while raising the bar for all students. Purpel (2004) goes so far as to argue that educators who lack such a moral grounding have no place in education.

One of the weaknesses of servant and moral leadership models though is the fact that they continue to place the leader at a point of privilege in which it becomes easy for leaders to fall into a savior/paternalistic role towards the community that they serve. What is suggested by servant and moral leadership models is that the role of the leader is to do what is best for their subordinates, while still maintaining authority, power, and control for themselves. 


\section{Transformational Leadership}

Transformational leadership begins to address the need for leaders to empower and develop those that they serve. A transformational leader focuses on "transforming" others to help each other, to look out for each other, to be encouraging and harmonious, and to look out for the organization as a whole. In this form of leadership, the leader enhances the motivation, morale and performance within the entire group.

The concept of transformational leadership was first introduced by James MacGregor Burns (1978) in relationship to his research on political leaders. Burns made the distinction between two different leadership styles: transformational vs. transactional. In transformational leadership, leaders and followers work together to build morale and motivation within the group. In transactional leadership, relationships are simply viewed as a series of gives and takes without any attention paid to the environment and culture that exists within the organization. According to Burns, the transformational style creates significant change in the life of people and organizations by altering perceptions and changing the expectations and aspirations of employees.

Building on the work of Burns, Bernard M. Bass (1985) suggests that the extent to which a leader is transformational should be measured in terms of the influence that they are able to have on their followers. Effective transformational leaders should be able to instill trust, admiration, loyalty and respect from their subordinates. The leader is able to transform and motivate followers by charisma, intellectual arousal and individual consideration. 
While transformational leadership does begin to address the importance of group visioning and the need for managers and administrators to facilitate leadership development across the entire organization, effective leadership is still viewed in a traditional authoritarian manner where personal traits of confidence, decisiveness, and responsibility are valued as important characteristics. Still lacking in the discussions of transformational leadership are aspects of shared responsibility, cultural relevancy, selfreflection, and humility.

Distributed Leadership

Distributed leadership (Elmore, 2000) continues to shift the role of leadership to a collective responsibility. Bishop, O’Sullivan, and Berryman (2009) suggest that especially in the school setting, the opportunities for and the success of change efforts are enhanced when a collaborative approach which brings together all stakeholders is used. In such an environment, the role of the administrator is to simply facilitate the discussion and decision-making process, thus providing a sense of decision-making authority, power, and control to the larger group. Distributed leadership begins to shift the notion of authority, power, and control as an individual prerogative to a collective group process.

In distributed leadership, the role of the administrator in facilitating and setting the vision for the group is extremely important. The administrator must be able to keep the group focused; otherwise, as Hall and Hord (2006) argue, reform efforts can fall apart as a result of individuals or cliques developing within the organization. Another 
weakness of distributed leadership observed by Hall and Hord is the fact that it becomes very difficult to sustain reform efforts when there is a change administrative leadership. Transformative Leadership

What continues to be missing in the descriptions of servant and moral, transformational, and distributed leadership is an acknowledgement and open discussion of the culturally biased ideologies which perpetuate ignorance, fear, and misinformation among educational leaders and the field of education as a whole (Evans, 2007; Murillo, 2002; Villenas, 2002). In an environment where students and families from culturally diverse communities are becoming more and more disengaged from the schooling process, there is a need for leadership in education to finally turn its back on deficitminded approaches and embrace cultural and linguistic diversity as educational resources (Cooper, 2009; Riehl, 2000; Shields, 2000; Shields \& Sayani, 2005).

Transformative leadership relies on the intervention of leaders who strive to counter marginalizing forces related to issues of race, class, gender, language, ability, and/or sexual orientation in their daily work as administrators (Cooper, 2009; Larson \& Ovando, 2001; Shields \& Sayani, 2005; Zhou, 2003). As Weiner (2003) states, "transformative leadership is an exercise of power and authority that begins with questions of justice, democracy, and the dialectic between individual accountability and social responsibility" (p.89). As noted in the previous chapter, this dissertation does not wish to replace the traditional leadership values of authority, power, and control with the transformative values of consciousness, resistance and praxis. Instead, as Weiner 
indicates, transformative leaders "must have one foot in the dominant structures of power and authority, and as such become 'willing' subjects of dominant ideological and historical conditions" (p.91) because "as actors inside dominant structures, transformative leadership must always make problematic the institutional power it wields" (p.93). The values of consciousness, resistance, and praxis which I present in this dissertation simply provide a transformative lens by which we can better understand the leadership experiences of administrators of color outside of the traditional values of authority, power, and control.

Transformative leaders become bridge builders who strive to "create caring and/or emancipator spaces for students, parents, teachers, and other constituents in the school organization" (Lopez, Gonzalez, \& Fierro, 2006, p.67; see also Cooper, 2009; Riehl, 2000; Shields, 2000; Shields \& Sayani, 2005). Unlike servant and moral leadership practices where there is still a divisive sense of "we vs. them," transformative leaders are individuals who fully understand and often come from the very communities that they are serving. As a result, transformative educational leaders often feel a deep personal responsibility to their community.

\section{Theoretical Framework}

The theoretical framework I used to develop the three transformative leadership values of consciousness, resistance, and praxis combines Critical Race Theory (CRT), decolonization, and Freirean critical pedagogy. I provide an overview of each of these theories and how they support the transformative leadership model which will be 
presented in the next chapter. While I have chosen CRT, decolonization, and Freirean critical pedagogy as the most applicable and relevant theories to frame this study, other theories, such as feminist theory (Blackmore, 2000b), have been used to challenge normative research on education and educational leadership.

Critical Race Theory (CRT)

Within education, CRT continues to challenge and deconstruct prevalent notions of fairness, meritocracy, color-blindness, and neutrality (Parker, Deyhle, \& Villenas, 1999). CRT has also been applied to the study of racial stratification in higher education to challenge dominant paradigms and place the educational experiences of students of color in broader social, institutional, legal, and historical contexts (Delgado, 1995; Teranishi, et al., 2009). CRT can be used to provide a strong theoretical framework to support transformative educational leadership pedagogy.

CRT focuses on the deconstruction of systems of racial oppression by placing issues of race and racism at the forefront of the discourse (Ladson-Billings \& Tate, 1995). As Solorzano and Yosso (2001) argue, "What is noticeably missing from the discussion of race is a substantive discussion of racism. Indeed, in moving beyond a discussion of race, we must name, define, and focus on racism" (p.472).

Discussing how CRT can be used to challenge normative framing, Teranishi et al. (2009) state that:

CRT challenges the notion that normative framing is an effective lens through which to examine educational equity issues. Essentially, 
normative framing is typically invoked to identify how different racial groups are unevenly distributed across a particular outcome (for example, participation or graduation). Alternatively, CRT perspectives focus on the needs of marginalized populations, which are often overlooked, as opposed to the agenda served by normative frameworks. Therefore, CRT can be an effective lens for examining and challenging normative paradigms, which define mainstream policy discourse and determine appropriate concerns for education research. (p.59)

Solorzano (1998) extends the challenge to normative framing by stating that "critical race theory in education challenges the traditional claims of the educational system and its institutions to objectivity, meritocracy, color and gender blindness, race and gender neutrality, and equal opportunity" (p.122).

CRT helps to challenge existing dominant paradigms of leadership and supports of a transformative leadership model. It does so through its five primary tenets: (a) the intersectionality of racism, classism, sexism, and other forms of oppression; (b) a challenge to claims of objectivity and neutrality within other dominant ideologies in educational research; (c) a commitment to social justice through the critical examination and transformation of discourse within education; (d) a valuing of experiential knowledge and the use of counter-narrative as a credible methodological tool to give voice and recognition to the experiences of marginalized communities; and (e) an interdisciplinary perspective to holistically address issues of racism (Buenavista, Jayakumar, \& Misa- 
Escalante, 2009; Cooper, 2009; Smith-Maddox \& Solorzano, 2002; Solorzano \& Yosso, 2001).

Decolonization

Fanon (1963) describes decolonization as a need to challenge and address the "raw, repressed, and reckless state in the lives and consciousness of colonized men and women" (p.1). Addressing the revolutionary plight and struggle of native Algerians, Fanon exposes the devastating effects of European colonization on the peoples of the African continent. Memmi (1965) also addresses the traumatic effects of colonization by arguing that:

We have seen that colonization materially kills the colonized. It must be added that it kills him spiritually. Colonization distorts relationships, destroys or petrifies institutions, and corrupts men, both colonizers and colonized. To live, the colonized needs to do away with colonization. To become a man, he must do away with the colonized being he has become. If the European must annihilate the colonizer within himself, the colonized must rise above his colonized being. (p.151)

What is important and significant about decolonization is not just in naming and talking about the struggle and its overall effects on colonized communities (Ngugi wa Thiong'o, 1986), but it is also about examining the emotional and psychological process that colonized individuals go through personally. As Smith (1999) describes, it becomes painfully problematic for native intellectuals as they criticize the role of Western 
education yet realize that they themselves have benefited from the colonized and privileged system that they are critiquing.

In order to use decolonization as a theoretical framework to support transformative educational leadership pedagogy, decolonization is defined as the psychological process that enables the colonized to understand and overcome the depths of alienation and marginalization caused by the psychic and epistemic violence of colonization (Strobel, 2001). Strobel goes on to state that, "to unlearn the internalized oppression brought on by colonization, there is a need to study how colonial identities are constructed by master narratives that serve to reinforce the social and economic and political structures that perpetuate unequal and unjust relationships of power" (p.vii).

This dissertation uses counter-narratives to balance the traditionally biased perspective of the master narrative which Strobel has described. In addition, the use of counter-narratives can be used to facilitate a healing process for colonized individuals. According to Strobel:

The healing process is simultaneously an individual and communal effort. What is summoned from the depths of one's soul comes from the wounded collective memory of colonized peoples, but so does the healing power that comes from woundedness. The memories must be shared with others. It is the telling that makes them available to the consciousness for further critical reflection. (p.51) 
By providing the opportunity for the administrators of color who participated in this study to share their stories, it is hoped that the power of the healing process is passed on from the administrators interviewed to those who read their stories and are able to relate to their experiences.

In the following passage, Tejeda, Espinoza, and Gutierrez (2003) situate the need to decolonize educational leadership pedagogy within the broader societal context of American society:

A basic premise of our call for a decolonizing pedagogy is that the dominant economic, cultural, political, judicial, and educational arrangements in contemporary American society are those of an internal neocolonialism produced by the mutually reinforcing systems of colonial and capitalist domination and exploitation that have organized social relations throughout the history of what today constitutes the United States." (p.13)

Leadership is decolonized when leaders of color claim a political identity, which is facilitated within the context of a politically engaged community of practice (Huiskamp, 2002; Lave \& Wenger, 1991).

Freirean Critical Pedagogy

Based on the works of Paulo Freire (1970) and supported by theorists such as Henry Giroux (1997 \& 2010), Ira Shor (1992), Peter McLaren (1997 \& 2000), and Antonia Darder (1991), Freirean critical pedagogy calls upon educators to critically 
question the inherently oppressive nature of educational systems. Criticizing what Freire described as a banking model for education in which students were mere recipients of knowledge which was passed down from the expert teacher, critical pedagogy shifts the emphasis from the role of the teacher as expert to the role of students as problem-posers and independent thinkers. As Giroux (2010) describes:

What Freire made clear is that pedagogy at its best is not about training in techniques and methods, nor does it involve coercion or political indoctrination. Indeed, far from a mere method, education is a political and moral practice that provides the knowledge, skills, and social relations that enable students to explore the possibilities of what it means to be citizens while expanding and deepening their participation in the promise of a substantive democracy. According to Freire, critical pedagogy affords students the opportunity to read, write, and learn for themselves-to engage in a culture of questioning that demands far more competence than rote learning and the application of acquired skills. (p.B16)

I use Freirean critical pedagogy as the basis for my critique of traditional leadership values which focus on authority, power, and control in order to present a transformative model which emphasizes the transformative values of consciousness, resistance, and praxis.

Freirean critical pedagogy supports transformative leadership values of critical consciousness because as Freire (1970) states, "in order to communicate effectively, 
educator and politician must understand the structural conditions in which the thought and language of the people are dialectically framed" (p.96). Borrowing directly from Freire, I use his notion of praxis as one of the essential values for transformative leadership:

But one does not liberate people by alienating them. Authentic liberation - the process of humanization - is not another deposit to be made in men. Liberation is praxis: the action and reflection of men and women upon their world in order in order to transform it. Those truly committed to the cause of liberation can accept neither the mechanistic concept of consciousness as an empty vessel to be filled, not the use of banking methods of domination (propaganda, slogans - deposits) in the name of liberation. (p.79)

Here, Friere uses praxis to distinguish between the more savior and paternalistic intentions of transformational leadership and the liberatory and humanizing intentions of transformative leadership. This critical connection which Friere makes between praxis and authentic liberation is one of the reasons why I include praxis as one of the three values in the model for transformative educational leadership pedagogy

\section{Conclusion}

In the next chapter, I build upon the review of the literature and the theoretical foundation which has just been presented to describe the methodology used for the study. In particular, I provide a description of counter-narrative and how, as a methodological 
tool, it can be used to more effectively acknowledge, validate, and honor the transformative leadership experiences of community college administrators of color. 


\section{METHODOLOGY}

In this chapter, I situate the methodology of counter-storytelling and counternarratives as research tools to effectively reframe the experiences of the community college administrators of color who participated in this study. I begin by providing an overview of how I will use counter-storytelling and counter-narrative as methodological tools. Then, I will describe the qualitative design, participant selection, and data collection process used to conduct the research as well as describe how the data was analyzed. I end the chapter with a discussion of my role as both researcher and participant and the strengths and limitations of the research.

Counter-Storytelling and Counter-Narrative

As discussed in the review of the literature, this study combines elements from Critical Race Theory (CRT), decolonization, and Freirean critical pedagogy to challenge traditional educational leadership pedagogy which use elements of authority, power, and control to describe normative leadership practices. In contrast, I introduce the elements of consciousness, resistance, and praxis to describe effective transformative educational leadership pedagogy. I will use counter-storytelling and counter-narratives as tools to voice the authentic experiences of community college administrators of color.

The use of counter-storytelling and counter-narrative as the primary methodological tool for this study is grounded in the belief that while more and more of the emerging research in educational leadership is beginning to challenge traditional 
notions of leadership, there is still a need to infuse the true voices and stories of administrators of color as part of the research on transformative educational leadership pedagogy.

Delgado (1989 \& 1993) describes a method called counter-storytelling and argues that it is both a method of telling the story of those experiences that are not often told (i.e. those on the margins of society) and a tool for analyzing and challenging the stories of those in power and whose story is a natural part of the dominant discourse. While Delgado's research was focused on the legal profession within the area of Critical Legal Studies, the application of counter-storytelling to other fields such as education, has been made (Solorzano \& Yosso, 2001).

Solorzano and Yosso (2001) describe four contributions which counter-narrative can provide to the current theory and research on education: (a) build community among those at the margins of society by putting a human and familiar face to educational theory and practice; (b) challenge the perceived wisdom of those at society' s center by providing a context to understand and transform established belief systems; (c) open new windows into the reality of those at the margins of society by showing the possibilities beyond the ones they live and demonstrating that they are not alone in their position; and (d) teach others that by combining elements from both the story and the current reality, one can construct another world that is richer than either the story or the reality alone.

Using counter-narrative as a theoretical and methodological tool is important to challenge the cultural bias which has inherently been infused within other research 
frameworks. The use of counter-narrative as a methodological tool will challenge positivist and postpositivist frameworks which "inherently reflect ideologies of control, hierarchy of knowledge, hierarchy of the researcher (as expert) and subject (as object), and the goal of finding a single "truth" and rejecting what is relative (win-lose)" (Nielson \& Suyemoto, 2009, p.85-86)

This dissertation explores and pushes the nature of counter-narrative as a methodological tool by using the actual stories of the research participants as the counternarrative. In previous studies, researchers have presented counter-narratives as fictional stories which are based on the data collected through real-life interviews. In advocating for the use of counter-narrative as a methodological tool, I would like to argue that there is no need to create fictional stories to represent the experiences of transformative leaders of color. The actual experiences, as shared by the individuals, are already counternarratives which do not need any further altering or fictionalizing. This is why the counter-narratives in chapters four, five, and six will be presented using as much of the individual's own words.

Ultimately, by presenting the counter-narrative, the goal of this dissertation is not to insist that the findings are generalizeable to any particular population or that my interpretation as the researcher is the only accurate interpretation of the participants' experiences. To the contrary, "stories and counterstories, to be effective, must be or must appear to be noncoercive. They invite the reader to suspend judgment, listen for the point 
or message, and then decide what measure of truth they contain. They are insinuative, not frontal; they offer a respite for the linear, coercive discourse..." (Delgado, 1989, p.2).

Consciousness, Resistance, and Praxis: An Identity Development Model for Transformative Leaders of Color

Using the theoretical framework described in the previous chapter, I developed an identity development model for transformative leaders of color which focus on the values of consciousness, resistance, and praxis. I present these three values to directly challenge and counter more traditional leadership values of authority, power, and control. By shifting the discourse and pedagogy from the more traditional and hierarchical to a more transformative and social justice model, the objective is to better understand and more accurately document the leadership experiences of transformative leaders of color.

Figure 1 provides a visual representation of the cognitive map which serves as the foundation for this model: 


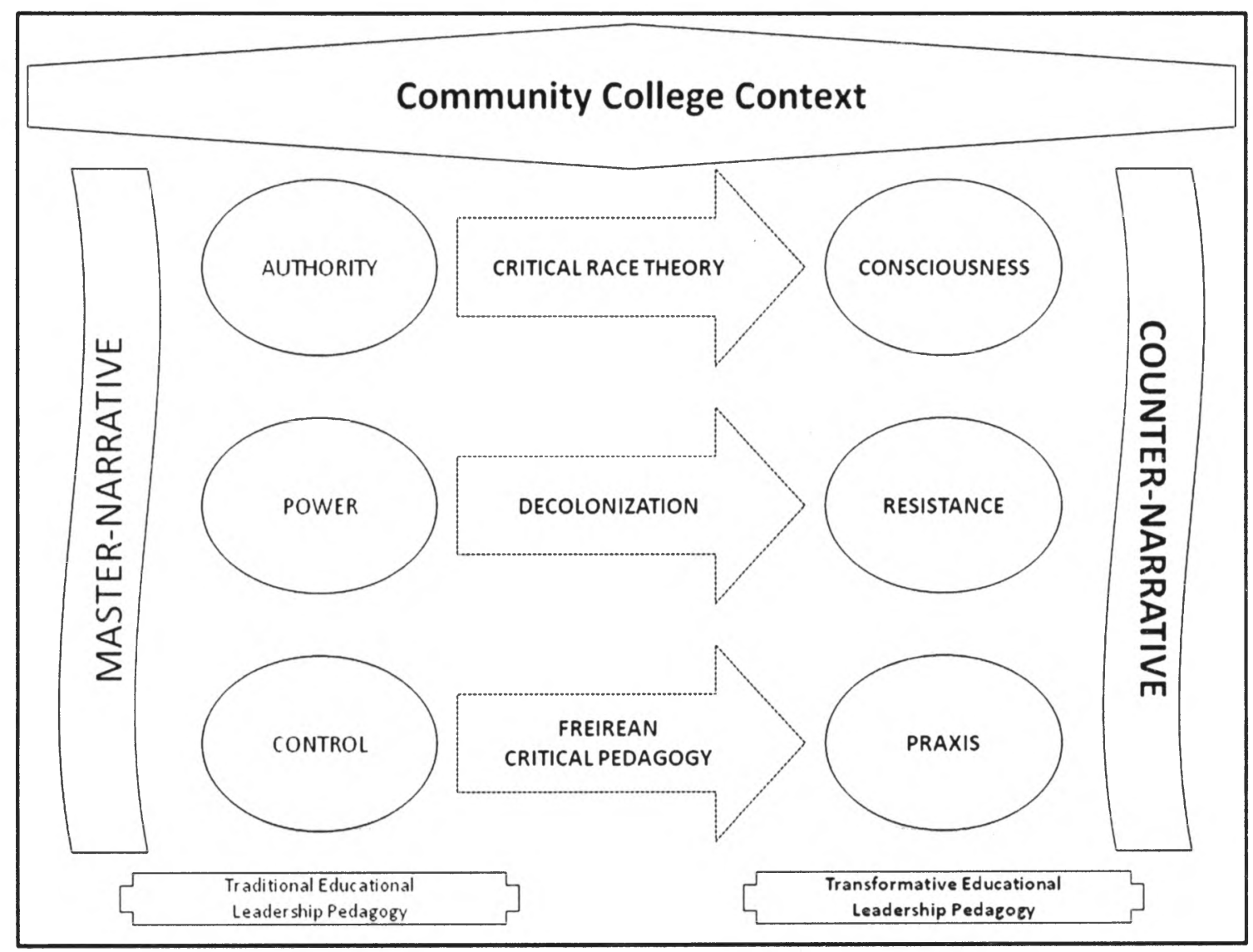

Figure 1. Cognitive Map.

\section{Study Design}

\section{Research Questions}

As mentioned in chapter one, the main research question for this study is: How can the transformative leadership values of consciousness, resistance, and praxis be used 
instead of more traditional leadership values of authority, power, and control to better understand the leadership experiences of community college administrators of color?

Focusing specifically on each of the three transformative values which have been presented, the following sub-questions are used to guide the analysis:

1. How do transformative leaders develop consciousness and what can be done to support the development of consciousness among administrators of color?

2. How do transformative leaders develop resistance and what can be done to support the development of resistance among administrators of color?

3. How do transformative leaders develop praxis and what can be done to support the development of praxis among administrators of color?

Overview of Study Procedures

The purpose of this study was to analyze the experiences of community college administrators of color through the lens of a transformative educational leadership pedagogy and to provide counter-narratives which challenge dominant notions of leadership as products of the mutually reinforcing systems of colonial and capitalist domination and exploitation which continue to influence contemporary American society (Tejeda, Espinoza, \& Gutierrez, 2003). The study deconstructs and reframes dominant notions of leadership to present counter-narratives which articulate transformative educational leadership pedagogy using the elements of consciousness, resistance, and praxis. This study also addresses important issues within the context of educational 
equity by describing, recognizing, and validating the experiences of administrators of color - voices that have historically gone unheard in educational research.

The findings from this study can be used to design support programs and interventions to address broader issues of underrepresentation and low rates of retention among administrators of color, especially within the community college setting. Understanding and documenting the experiences of administrators of color will be important in designing culturally relevant educational leadership preparation programs. In addition, this study also advances the use of counter-narratives as a methodological tool for educational research.

The study involved individual semi-structured interviews with eleven community college administrators of color. Potential participants were contacted and interviews were conducted between December of 2009 and April of 2010. Participants were interviewed for approximately one hour each about their leadership experience as a community college administrator of color (see Appendix A: Semi-Structured Interview Protocol). While the established interview protocol was used as a guide, the semistructured interviews were carried out more as conversations and focused more on giving the participants opportunities to tell their unique and individual stories.

\section{Population and Sample}

The study included a sample of eleven research participants: (a) five community college senior administrators (CEOs/Chancellors/Presidents/Vice Presidents) and (b) six community college middle managers (Deans/Directors/Managers). 
The study focused on the experiences of community college administrators of color and was purposive in having the two sub-groups of senior administrators and middle managers. The justification for these sub-groups was to compare the differences between the experiences of the senior administrators and the middle managers.

Table 1 shows the eleven participants and their respective colleges and districts. The participants come from seven different community colleges and one district-level CEO. The sample represents six different community college districts within the San Francisco bay area. Pseudonyms are used for participant names, colleges, and districts in order to preserve participant confidentiality.

Table 1. Participants by College/District (Pseudonyms).

\begin{tabular}{lll}
\hline Name & College & District \\
\hline Rochelle Simpson & Crestview College & Middle Peninsula CCD \\
Matthew Pearson & South Peninsula Hills College & South Peninsula CCD \\
Sherry Singleton & Mountain Valley College & Baypoint CCD \\
Andres Rodriguez & Silicon Valley College & South Bay CCD \\
Rebecca Pacheco & District Office-SBCCD & South Bay CCD \\
Miguel Suarez & East Hills College & South Bay CCD \\
Liliana Rojas & Silicon Valley College & South Bay CCD \\
Fred Chieu & Downtown College & Bay Bridge CCD \\
Karen Hamamoto & East Hills College & South Bay CCD \\
Nathan Ocampo & Downtown College & Bay Bridge CCD \\
Tracey Vu-Kwon & Bayside College & East Bay CCD \\
\hline
\end{tabular}


The colleges and districts range from both small and large colleges, urban and suburban service areas, as well as predominantly high and predominantly low socioeconomic communities of the bay area.

The key demographic qualities that were considered as inclusion criteria for the study included: (a) a representative sub-group of senior administrators and middle managers; (b) representation of Latina/o, African American, Asian voices within each sub-group; and (c) participant gender/sexual orientation..

Table 2 shows the different positions that the administrators held at the time that they were interviewed and whether their backgrounds were in the areas of student services or instruction along with information regarding their race/ethnicity, gender, and identification as lesbian, gay, bisexual, or transgendered (LGBT).

Table 2. Participants by Position/Area/Race/Ethnicity/Gender/LGBT Identification.

\begin{tabular}{llllll}
\hline Name & Position & Area & Race/Ethnicity & Gender & LGBT \\
\hline Rochelle & Vice President & Instruction & African-American & Female & Yes \\
Matthew & Director & Student Services & African-American & Male & Yes \\
Sherry & Manager & Student Services & African-American & Female & Yes \\
Andres & Vice President & Instruction & Latina/o & Male & No \\
Rebecca & Chancellor & Student Services & Latina/o & Female & Yes \\
Miguel & Director & Student Services & Latina/o & Male & No \\
Liliana & Dean & Instruction & Latina/o & Female & No \\
Fred & President & Student Services & Asian American & Male & No \\
Karen & Vice President & Instruction & Asian American & Female & No \\
Nathan & Dean & Student Services & Asian American & Male & No \\
Tracey & Dean & Instruction & Asian American & Female & No \\
\hline
\end{tabular}


Participant recruitment and selection utilized snowball sampling and community nomination, initially identifying community college administrators of color in the local bay area (San Francisco/San Jose/Oakland metropolitan area). Those that were interviewed were then asked to nominate other colleagues who would be ideal candidates for participation in the study.

Drawing from grounded theory and the dual role I was able to play as both researcher and participant, participant recruitment and selection involved intentionally seeking participants who fit the definition for transformative educational leaders provided in chapter one. As a result, simply being a community college leader of color did not automatically make an individual a potential research participant.

\section{Data Collection}

Potential study participants were initially contacted by email and/or phone using a pre-approved recruitment script. Participants who accepted the invitation to participate in the study were then contacted to schedule interviews for dates, times, and locations that were convenient for the research participant. Prior to the beginning of the each interview, participants were provided with an informed consent form (see Appendix B: Informed Consent Form).

Due to the qualitative semi-structured interview design and the fact that the goal of the study was to give voice to the stories of the individuals and their experiences as it relates to their leadership experiences as administrators of color, the study did not utilize any pre-existing data collection instrument. The main data collection instrument 
consisted of semi-structured interview questions (see Appendix A: Semi-Structured Interview Protocol). Interviews ranged in length from approximately forty-five minutes to an hour and thirty minutes. All interviews were audio recorded and later transcribed.

\section{Data Analysis Procedures}

Interview transcripts were reviewed throughout the data collection process in order to use initial data analysis to inform subsequent interviews. While the a priori (selective) codes using the three transformative values of consciousness, resistance, and praxis were used for initial coding, inductive (open) coding also took place as I reviewed interview transcripts throughout the data collection process.

While elements of consciousness, resistance, and praxis were evident in all of the counter-narratives, part of the data analysis involved trying to capture the most salient examples of transformative educational leadership pedagogy conveyed in each of the stories. The data analysis presented in chapters four, five, and six is organized based on coding using the transformative values of consciousness, resistance, and praxis. The counter-narratives presented in each of the chapters will contain elements of all three transformative values, but they have been placed in a particular chapter because there is something tangible in the counter-narrative which specifically focuses on the theme associated with the transformative value being presented in that chapter.

Role of the Researcher

I had a pre-established working relationship with a majority of the research participants because of my current position as a middle manager at one of the community 
college districts included in the study. As a community college administrator of color myself, there were numerous situations where I played the role of both researcher and participant. Due to the qualitative and participatory nature of the study, the pre-existing working relationship and my ability to serve as both researcher and participant was advantageous in that it resulted in greater trust and openness during the interview process. I also used my dual role as both researcher and participant in using my personal experience to provide the example of the difference between the master-narrative and the counter-narrative which was presented in chapter one.

As the primary researcher, I performed all of the data collection and transcription of interviews. In addition to audiotape recordings of interviews, I also maintained a reflective journal throughout the data collection process to keep track of emerging themes and anecdotal data that could be incorporated as part of the data analysis process.

\section{Strengths and Limitations of the Research}

As stated earlier, the goal of this study is not to present a set of generalizations and findings that would provide across the board applicability to the leadership experiences of transformative leaders of color. In terms of the implications and the applicability of the findings, I leave it to the reader to make those connections to the stories and experiences that are presented. The goal of presenting the counter-narratives using as much of the participants' own words is to depict their counter-narrative in a way that is authentic and genuine. It is my hope that this study will encourage the use of 
counter-narrative and counter-storytelling as a way to recognize and validate the experiences of transformative leaders of color.

Limitations of the study include the geographical limitation of participants within the local San Francisco Bay Area. Future research expanding to other community college administrators of color from throughout the state and throughout the country will provide greater insights into the leadership experiences of transformative leaders of color. Further research should also include longitudinal studies which follow and document transformative leaders of color over an extended period of time in order to chart an individual's leadership development over time. By introducing the use of counternarratives to present the stories of the eleven community college administrators that took part in this study, it is hoped that more and more research on community college administration and leadership will utilize counter-narrative and counter-storytelling in order to give voice and legitimacy to the experiences of transformative leaders of color. 


\section{CONSCIOUSNESS: THE DEVELOPMENT OF TRANSFORMATIVE LEADERS OF}

\section{COLOR}

An important value to the model for transformative educational leadership pedagogy which I have presented is consciousness. Grounded in Critical Race Theory, I describe consciousness as a process in which transformative leaders of color (a) go through a crucial awakening, (b) come to an acknowledgement of the centrality of race and racism in their overall leadership identity and leadership practice, and (c) begin to connect their experience and identity to that of their students, seeing their power to address issues of inequity as transformative leaders of color.

The six counter-narratives which will be presented in this chapter will be those of the middle managers who participated in the study. This group of participants include one manager, two directors, and three dean-level community college administrators of color. I present each of the characters' stories individually in order to preserve the authenticity and uniqueness of each of their experiences and to provide the reader with an opportunity to connect with each character. It will be in the final chapter of this dissertation where I will provide a summary and recommendations of how to better support the leadership identity development process for transformative educational leaders.

The first counter-narrative will be that of Liliana. Liliana's story will be important as we look at developing ways to encourage administrators of color to reach a 
point of awakening. From Liliana, we will then meet Tracey and Sherry whose counternarratives emphasize elements of acknowledgement as part of their transformative leadership identity. The last three characters who you will meet in this chapter will be Miguel, Matthew, and Nathan. We will see in their counter-narratives critical elements of connecting as they develop their consciousness as transformative leaders of color.

Awakening

Awakening refers to a point in time in which a leader realizes the urgency and need for a personal commitment to action. With this awakening, the educational leader can no longer simply sit idly by and let societal forces of hegemony and social reproduction continue without taking action. Awakening can be described using the following passage from Freire (1970):

The revolutionary leaders must realize that their own conviction of the necessity for struggle (an indispensable dimension of revolutionary wisdom) was not given to them by anyone else - if it is authentic. This conviction cannot be packaged and sold; it is reached, rather, by means of a totality of reflection and action. Only the leaders' own involvement in reality, within an historical situation, led them to criticize this situation and wish to change it. (p.67)

For community college administrators to engage in transformative educational leadership pedagogy, they must first realize that there is something fundamentally wrong with how educational systems are currently structured, and with this awakening, they must then 
begin to use their position as an educational leader to begin questioning and deconstructing the organizational and leadership frameworks which currently exist. Liliana Rojas

Liliana's counter-narrative as a new Latina community college administrator focuses on her struggle with feeling as if she needs to justify her place in her administrative position more so than other administrators who are members of the dominant group. Liliana's experience is one of feeling as if she is an outsider and that there is a double standard which she is being held to as an administrator of color:

I think we feel that we have to justify why we're here... that we really have to explain it... why we're here... it's not that I was given a pass because I am a female of a minority group... I know somebody... blah blah blah... but these are my credentials... this is what I've done... and something that would never be questioned for somebody from another ethnic group would never be questioned... vs. somebody from a minority group, we always have to because it's questioned...

What we see in Liliana's comments is common for transformative administrators of color as they engage in the awakening process. As part of her awakening, Liliana gains a heightened awareness and sensitivity to the difference between how she is viewed and judged as an administrator versus her white male counterparts.

In describing the double standard that she is feeling as a leader of color, we also begin to see some of the deep rooted insecurities that often plague new administrators of 
color and which feed into Liliana's feelings of self-doubt. A recurring theme in her counter-narrative is the sense of needing to prove herself and establish credibility:

What I feel is that I have to be very firm on my decisions. And I can't be wishy-washy about it because then my credibility will be questioned... and I think that the credibility being questioned still comes with being somebody from an ethnic minority background... being one of very few... it just happens.

As a result of feeling as if she always needs to be firm on her decisions or else have her credibility questioned, Liliana ends up spending a lot of time debating her leadership actions and going back and forth on in her head before actually making a decision. While this may seem from the dominant perspective as a lack of self-confidence and doubt in her own capabilities, Liliana attributes her need to take the time to fully consider every leadership decision as part of the double-standard that she is held to as an administrator of color.

In order to build self-confidence and belief in her own capabilities as a newer administrator of color, Liliana describes the need for effective mentors who can serve as role models:

It's been difficult as far as finding individuals, in my experience, individuals that I can say, okay, this person really... I latched onto this person as a mentor. I think now that I'm here, it's where I'm finding 
more... the few Latinos or people of color... we kind of help each other and that makes it easier.

When you are with people of your own group, that have gone through the same, you don't have to explain... because they just know... they just know that you've also gone through the same challenges, because they've gone through the same challenges.

The latter part of Liliana's comments underscores the need for culturally focused mentorship programs. In the review of literature, Hull and Keim (2007) advocated for the importance of mentoring in preparing community college administrators, but what we see from Liliana's counter-narrative is the importance of having mentors who share similar cultural backgrounds. Being able to share experiences with individuals from their own cultural group provides a therapeutic value by providing leaders of color the opportunity to vent and openly talk about their experiences in a safe and non-threatening environment.

\section{Acknowledgement}

Transformative educational leaders must also be grounded in an acknowledgement that race matters and that race and racism are social constructs which cannot be separated from discussions of other forms of oppression. As Solorzano and Yosso (2001) suggest in their discussion of CRT, "what is noticeably missing from the 
discussion of race is a substantive discussion of racism. Indeed, in moving beyond a discussion of race, we must name, define, and focus on racism" (p.472).

Far too many times, race and racism have been reduced to individual actions instead of being viewed as part of the larger social construct. This reduces the responsibility to addressing individual acts of racism, instead of acknowledging that issues of racial and social inequities are woven into the very fabric of how our society functions and operates on a daily basis. Educational leaders who practice transformative educational leadership pedagogy must acknowledge the centrality of race and racism as social constructs which have shaped and continue to affect their role as transformative leaders of color.

Tracey Vu-Kwon

Tracey's counter-narrative focuses on her ongoing challenge to balance traditional leadership expectations with the cultural norms and values of her Vietnamese culture. It is through her participation in a culturally focused summer leadership development program that she develops an acknowledgement of her transformative leadership identity as a female Vietnamese American administrator.

As an academic dean at Bayside College, Tracey's very path to her current leadership position is what she describes as "non-traditional." Tracey began her career as a classified staff member, working in a community college assessment office. With her own initiative and the support of her supervisors, Tracey began to take on more and more responsibilities and pursue career advancement opportunities. The support she received 
from one of her supervisors in particular was something that Tracey recalled as having a positive impact on her leadership development:

She... I think was probably one of the bigger impacts in me being able to maximize the opportunities and really take it and move on further with it... she enabled me to participate even at a classified level, in a classified position, in a manner where it didn't matter what position I was in... she gave me a lot of responsibilities and I participated statewide.

As we continue to discuss the leadership development of administrators of color and effective educational leadership pedagogy, it is important to note from Tracey's experience the impact that supportive supervisors play on the leadership development of their staff.

While at Bayside, Tracey had the opportunity to participate in a summer leadership conference coordinated through Leadership Education for Asian Pacifics, Inc. (LEAP) and Asian Pacific Americans in Higher Education (APAHE). It was this experience that provided Tracey with the acknowledgement of the importance that her cultural background played in terms of her leadership identity. As Tracey reflects:

That training that I went through with LEAP and APAHE that summer, was the perfect timing. I was at a point in life where I just needed to kind of get myself together and understand where I needed to go for myself and find my own personal growth and personal development... and so it was very enlightening because I think they had you go through activities where 
you talk about your values and what are your values culturally and how did you get them... and of course it's cultural and you can be white or whatever and it's still cultural.

But what is it about culturally focused educational leadership development programs for administrators of color that makes them so different from more traditional leadership development programs? And why are more of these programs needed? According to Tracey:

I've done a couple of leadership things through state organizations... one when I first started at Bayside and one last year... and they're helpful, but I don't think it was as personal and looking at your background and cultural perspective as the leadership program through APAHE and LEAP during the summer.

What we are starting to see in Tracey's comments is critical consciousness beginning to form. What made Tracey's experience with the APAHE/LEAP program so powerful for her was the fact that it provided an acknowledgement and validation that her cultural identity as a Vietnamese American comes with leadership values that she can use as she develops her transformative leadership identity. While these values may not necessarily be congruent with the more traditional leadership values of authority, power, and control, the APAHE/LEAP program allowed her to be okay with letting her cultural values influence her leadership identity: 
I think what's really been the most valuable was just understanding where you came from and what components of you do you need to have in order for you to be at your best and your strongest... and I know that family is really important to me and so it's not just family at home... but family... kinda building that sense of family here in the workplace.

I think it's just a matter of being able to take that out of your personal and put it into your work and try to incorporate it and understanding that for other people it's not the same... realizing that people don't all have that same perspective... that sense of family and togetherness is not always how someone was brought up so that might not be something that they would build into what they need to be a good leader.

What I find particularly profound in Tracey's reflection is not just the fact that she has determined that it is okay for her to define her own leadership practice according to her own values, but the critical acknowledgement she makes in that last section of the passage where she acknowledges that there are multiple perspectives and possibilities into defining a "good" leader.

Being female and Vietnamese, Tracey has also faced numerous experiences in which she has had to deal with various negative stereotypes and preconceived expectations that both colleagues and members of the broader community place on her: 
It's unusual... I'm Vietnamese and so I think I come in and most of the time what I get hit with is the Asian stereotype of me being petite, and kind of quiet and demure... I'll do what I need to do... so you have that stereotype that you are working with. I think what usually shocks people is that I actually do speak up and I am very... once I get on to particular topic or issue... I can become very vocal. So I think that is very unusual.

Unusual for whom? Part of the importance in sharing Tracey's counter-narrative, as well as the counter-narratives of the other transformative leaders of color in this study and the counter-narratives of all administrators in general, is to confront this issue of feeling "unusual" or "out of the ordinary" which administrators of color often describe.

Why should Tracey think that her situation is unusual, when it is an experience that is shared by many other leaders of color? It only seems unusual and out of the ordinary because the counter-stories of leaders of color are not yet a normal part of the discourse on educational leadership.

While Tracey's acknowledgement was sparked by her participation in a culturally focused educational leadership development program such as the one offered through LEAP and APAHE, we also begin to see Tracey engaging in the process of connecting as she describes her need to connect and reach out to other communities outside of her own: You know... it's just your world, so to keep having the discussions within that world, you have a skewed perspective on what is happening... and so being a part of groups and networks, that's what I'm looking for. 
Tracey's desire to connect her experience with those of members of other groups is an example of her moving into the third component of connecting and thus completing the full cycle of consciousness for transformative educational leaders.

\section{Sherry Singleton}

Sherry's counter-narrative focuses on the tendency among administrators of color to be overly critical of themselves, the element of humility and how it sometimes has the negative effect of holding administrators of color back from advancement, and the loneliness and isolation that comes from being a transformative leader of color in a predominantly white institution. As a middle manager, Sherry's counter-narrative will be of particular importance in terms of recognizing the specific struggles faced by newer administrators of color and her story can inform the design and creation of culturally responsive leadership development programs which adequately address the specific needs of emerging transformative leaders of color.

Sherry's consciousness surrounding issues of social justice and equity were sparked while she was an undergraduate in college:

I was a student activist. I was at Madison-Wisconsin in the late 90s when there was some mock slave auction that some fraternities held. And there was a fraternity from Southern Illinois that drove all the way up to disrupt the African storyteller class. There were these major racist things and so I started cutting my teeth in activism and believing in bettering the situation. So that was like this drive for me. 
The consciousness she experienced at Madison-Wisconsin is what then led Sherry to a career in college student personnel services, and more specifically, in working with providing services for students with disabilities.

What is particularly significant in Sherry's counter-narrative is the mixed messages she has received from her supervisors and how this leads to her being overly critical of herself and unsure of her leadership abilities. Unlike Tracey who had a supportive supervisor that encouraged leadership and professional development, Sherry's experience was quite the opposite:

I think the whole way along, I get two messages... or more than one message. So one message is "Wow, you are really doing this well"... "I really enjoy working here"... "I'm really glad you're helping to coordinate us"... and then on the other hand, I'd get resistance... "What the hell do you know?"... "You're not 50-something years old approaching menopause and white. You don't know LD testing so why are you telling me that I need to enter this stuff into the computer and I don't like to use the computer"... “I don't think I like you. I don't like how you're coordinating"... "I don't think you know what you're doing”... So I get that message and then from say my boss, I get sometimes "Yeah, you're doing ok," and "Yeah, that's the right call to make in all these situations," but silence when it came to real difficulties with some of the more seasoned faculty in the area. 
Sherry began to rely on the presence of allies in order to build her confidence and trust herself and her leadership abilities:

So I think for me there were some good reasons to not quite be sure of what my skill level was around disability issues, but in time I started to know that I was doing a good job... at least on my campus. My circle of people that I know and feel comfortable working with is really big.

Yet despite the presence of allies and the building-up of her own self-confidence, Sherry's counter-narrative provides a firsthand and personal glimpse into the emotional and psychological toll that administrators of color endure as part of their leadership reality:

So I guess I knew I had a good amount of knowledge, but I guess it's hard because you do have a voice that says don't get too big for your breeches... don't think that you're all that. At any moment in time, they may pull some card and take it all away and say, well you're not... you're just a black girl... that we let you have this position... but you may not keep it all the time... so you better stay humble and you better work hard because you never know when that rug will get pulled out from under you. Drawing a connection to Liliana's counter-narrative, this "outsider" perception and the fear of "them" being able to pull some card and take it all away, is an important part of the counter-narrative for administrators of color. Oftentimes, as administrators of color, we are expected to be confident, assertive, and strong-willed by virtue of the leadership 
and decision-making roles that we assume as administrators. But what happens, and how are the leadership identities of administrators of color impacted, by the larger, broader, systemic, and ongoing affects of marginalization, racism, sexism, and other forms of oppression that our communities continue to experience?

For Sherry, she describes her leadership development and journey towards consciousness as a series of different stages similar to what Smith (1999) and Fanon (1963) described as the different levels experienced by native intellectuals in their progress towards consciousness:

I think that coming into management circles... because I am fairly new in the management circle... I did have to go through different stages... Like one stage was being very sensitive about the things people said.... The negative connotations to their comments or condescension in their comments that I perceived to be. I had to go through a process of sifting and not paying attention to all of it and figuring out like what the most important thing was in each situation and then kind of learn that I am who I am regardless of what I'm doing and so I'm going to do what I believe is right and those other things that somebody says are really important for management, I'm not gonna do, I'm just not... and I'm ok with it. It has taken me time, but I accept myself and my mom always taught us to not strive for ordinary and not strive for just fitting in... not to say don't fit in, but... because I was raised for the first half of my life in white suburbia... 
where we were the only people of color around... and so she had to prepare me for that experience... that you're not going to be able to be this molded cookie-cutter... like everyone else... and so that makes it, even now, okay to have a different leadership style... so it is a little more collective... definitely collaborative.

As a result of this individual process and self-reflection, Sherry is now able to come to terms with the fact that her leadership style is not exactly that of what the dominant culture expects or has traditionally valued. In her process towards consciousness, Sherry has developed a level of acknowledgment where she now knows and is comfortable with who she is as a female African American administrator and the qualities that her cultural background brings to her leadership identity.

Sherry's journey to consciousness was an extremely emotional process, and one of the recurring themes which Sherry's counter-narrative vividly captures is the sense of loneliness and isolation often felt by transformative leaders of color:

There would be times where I would go back to my office and cry... and I would let my boss know what was happening... not get any real support or affirmation from him... just like "wow, that's tough"... and that was pretty lonely... and I remember feeling like I was so different from him. There was no common ground.

Yet as difficult and as emotional as her experience may be, Sherry goes on to state that this is a reality that she is not complaining about, nor is she seeking pity for. Instead, she 
views this reality as part of her social responsibility and her responsibility to a cause far greater than herself:

I understand the third shift thing, but from my research with the other mothering, I also realize it doesn't take that much to be caring. And I think that there is a way that we can do it. And I think that we, for all the things that we've been through as our different groups... in our colonial experience here and where we're from... I think that we owe it to each other to support each other as much as possible... especially professionally... educationally... with advancement.

\section{Connecting}

The third element of connecting focuses on the need for transformative educational leaders to connect with other oppressed groups and value the varied lived experiences which members from marginalized communities bring with them to the educational setting. Transformative educational leaders must challenge the dominant hegemonic forces of social reproduction and work to include more culturally relevant curriculum and pedagogical practices in our community colleges. Programs and services for underserved populations must capitalize on the cultural backgrounds and experiences of students of color instead of assuming traditional deficit-minded approaches.

Solorzano and Yosso (2001) describe the centrality of experiential knowledge within a framework of CRT by stating that, "critical race educational studies view this knowledge as a strength and draw explicitly on the Student of Color's lived experience 
by including such methods as storytelling, family histories, biographies, scenarios, parables, cuentos, chronicles, and narratives" (p.473). For educational leaders, this would involve listening and valuing the varied and unique experiences of marginalized student populations and including these lived experiences as part of the regular conversations that occur when critical discussions about curriculum and institutional effectiveness are taking place.

\section{Miguel Suarez}

Miguel's counter-narrative, similar to that of Tracey, is one which focuses on the importance of acknowledging and being critically conscious about one's values and the role that one's cultural background plays in one's leadership praxis. What distinguishes Miguel's counter-narrative from that of Tracey is that we begin to see in Miguel's counter-narrative a tangible and real example of how he uses his consciousness to engage in critical forms of resistance. Active and intentional forms of resistance which attempt to transform and reframe the very discourse of the institution into being more transformative.

For Miguel, the decision to work as an administrator of color in the community college setting, was rooted in his own personal experience:

Coming from a UC and also a private Christian university, there still is very much that sense of elitism and so experiencing that as a student, but also being a community college student at one time myself, I think the 
mission of the community college is exactly what we need here in California and across the nation, so it was my calling.

It is important to distinguish Miguel's reference to his decision to become a community college administrator as a "calling." For transformative educational leaders of color like Miguel, we view our responsibility to serve marginalized and oppressed communities not just as a job or a career, but instead as something greater, like how Miguel refers to it as his calling.

There is also a very strong sense of self and awareness towards his cultural identity present in Miguel's counter-narrative. For instance, Miguel strongly recognizes the role that his cultural identity has on his leadership practice:

As an administrator... or as a Latino administrator... I'm not sure that you can separate them out because I think your identity is part of who you are as a person. Being able to be comfortable in your own skin... but also the cultural traditions that we grow up in shape who we are as people... that it's a part of who we are as people... so I'm not so sure that you can separate out the fact that I am a Latino but also an administrator... In addition to acknowledging the role of his Latino cultural values in developing his leadership identity, he extends those values to something bigger than just his responsibility to the Latino community:

I think the first thing is just my personal values, values of fairness, values of doing things the right way... ethically... at least as it pertains to my job 
responsibilities... just really having that strong sense of self... considering that I am a Latino administrator, but also my values being bigger than that... I want to be able to reach across to all students, independent of race, gender, ethnicity, sexual orientation... and just really be a servant to students... and just try to be a model to students.

In addition to highlighting the importance of connecting as a critical component of consciousness, referring to his role as a servant to students allows us to see how Miguel has aligned his leadership praxis towards servant leadership models as opposed to more traditional authoritative and hierarchical leadership models.

Providing an example of what Miguel defines as courageous and transformative educational leadership, he describes the personal challenges he has faced and his experience as an administrator committed to ensuring that higher education is available for all students, even those who are undocumented:

It's complex, because... and I can give you some recent examples where there is a whole political mindset against undocumented students and whether we should even be serving them in the first place... and the counter-argument is always... we have our own students who are citizens that need services, so why should we focus resources and energy on those who are not even citizens of this country... and so what it becomes then is it becomes something where as a leader, and I'll speak from my own experiences, you can make the decision on whether you want to fall into 
that and say yeah, that's right, we should focus our resources and energy on our own students who are citizens... or... and this is where I think it takes courage as a leader, to say, yes, we have a group of students who are undocumented, but they are here, they are seeking services, and do they have the rights to equality that all the other students have... and so it becomes a personal decision.

I think that's really the defining line... is does a person or does a leader want to be courageous enough to try and advocate for students who they know are marginalized... and it's a decision... it really is a decision... and some people will say no, that's not something I want to invest my time in... and other leaders will say we should put policies in place that serve all students equally... and that's the defining line.

It is this drive and conviction in countering marginalizing forces related to issues of race, class, gender, language ability, and/or sexual orientation in their daily work as administrators that defines transformative leadership and distinguishes it from the other leadership models reviewed in chapter two.

And what is it that drives administrators, and specifically administrators of color, to take that step over that defining line which Miguel has described in order to commit themselves to transformative work? For Miguel, as it is the case for others, it is the result of their own personal experience of being marginalized and oppressed: 
I don't think you can ever truly know how it feels until you've experienced it yourself... you can read it in textbooks... you can hear other peoples' stories... but until you have actually experienced it yourself from being marginalized or just having any kind of prejudice exercised against you... it hurts... it hurts and it's not a fun thing to go through, so with that being said, I think that's why I'm so adamant about equality for all students because again, being in an administrative position now, I never want to levy my power against another group because it was done to me.

As a transformative leader of color, Miguel's counter-narrative is important because it focuses on the fact that his goal is not to simply gain access and entry into administrative leadership positions, but instead, it is to transform the very institution so that we are able to better serve the needs of marginalized and oppressed communities.

\section{Matthew Pearson}

Matthew's counter-narrative documents his journey through consciousness as a transformative educational leader. From his early experiences in Upward Bound and other Title IV and Title V programs for underrepresented, low-income and marginalized student populations, to his experiences as a gay black man, Matthew's counter-narrative emphasizes the connections and intersections of his multiple identities and how the intersections of those identities all inform his role and identity as a transformative leader of color: 
I am a man... I am a black man... I am an emerging administrator of color... I am a gay man... I think your research should report the intersections. I live at the intersections of those identities... and so I want to be sure that your research reports that authentically and accurately because I think that perhaps there may be someone reading your dissertation who can benefit from the honest and authentic report of the intersection of those identities... and they ALL inform my role as an administrator of color. They ALL inform it.

Matthew's statement is profound, and while the focus of this study is primarily on the experiences of transformative leaders of color, it has always been my intent to ensure that the intersections of gender, sexuality, class, and any other form of identity are recognized as inseparable and important aspects which contribute to the overall experiences and leadership identities of administrators of color.

Similar to Sherry, Matthew's consciousness occurred during his undergraduate experience:

I actually attended a historically black college in Louisiana... in Baton Rouge, Louisiana... Southern University... and it was the moment for me... it was the moment that changed my life. In terms of learning about black accomplishment and black contribution and seeing the parade of African American people around campus with their advanced degrees and their Ph.D.'s and their Ed.D.'s and how that was role modeled for me... 
Along with this awakening and acknowledgement of his black identity came with it a sense of connecting to the experiences and struggles of other marginalized communities:

But what I learned in that process is a celebration of black culture and a celebration of my culture is not a dismissal or negation of another person's culture. And if fact, it gave me the permission to allow persons to celebrate and revel... and relish... in their own cultural contribution and accomplishment... be it race... be it gender... be it any other identity group.

In fact, Matthew goes on to emphasize the importance of reaching outside of our own communities:

And I think sometimes the kind of cultural building and access and knowledge that we need to acquire oftentimes needs to be done outside of our community. I mean it would have been easier for me to go to a black church or the NAACP, but in the process, I am doing the work that needs to be done and I'm also learning cultural capital and information about another community, another culture, another religion.

As a critical and transformative educational leader, Matthew's counter-narrative emphasizes the importance of reaching out to other marginalized and oppressed communities in order to build common ground and mutual understanding of each others' struggle. 
In terms of seeing his role as larger than just himself, Matthew sees his responsibility as something that he does not have the time, nor the choice, to consider, but instead it is a social responsibility which he owes to those who have come before him and those that will come afterwards:

I don't have time to ask myself the question, "why me" or "should I be doing this work"... I am in the moment... I have prepared myself academically... I have surrounded myself with the paper as they say... I've gotten the degrees... and I feel like I am the best one to advocate for students of color... for marginalized people. I am the best one... And I owe it to the ancestors to take the baton and to do what I can do at this time in my life to make it easier for generations that come after me.

\section{Nathan Ocampo}

Nathan's counter-narrative focuses on the importance of alliances as he develops his consciousness and lives his life as a transformative leader of color and pedagogue. In his counter-narrative, we get a glimpse into how Nathan's consciousness has developed through a process of awakening, acknowledgement, and connecting to the struggles of other marginalized groups. Nathan's counter-narrative also provides a description of how critical educational leaders deal with the emotional labor that comes along with realizing that one's work towards social justice and equity is so much larger than one's self, and is instead a social responsibility that they owe to their community. 
Nathan's awakening in terms of his cultural identity, similar to Sherry and Matthew, begins as an undergraduate student. For Nathan, this was while he was a student at San Francisco State University (SFSU). Though a biology major, Nathan's consciousness was sparked by his experience in the Ethnic Studies program at SFSU:

I think for me it started even before I saw myself as an administrator or as an educational leader. It started... going back to that experience of getting to know a part of me that I didn't know... and that was experienced in San Francisco State in the last 18 months in terms of my exposure to Ethnic Studies... and then all of the sudden I noticed that I just started to wear it on my sleeves. That it defined me. Like I started to learn more about what it meant to be Filipino or Filipino American and that experience.

In the next passage, Nathan reflects on his shift from the awakening at SFSU to a sense of acknowledgement in which his race and ethnicity mattered and that race and racism were social constructs which could not be separated from discussions of other forms of oppression. Nathan describes how this acknowledgement meant that he now brings his identity to the table in every interaction or situation that he is placed in:

Early on during that period I just kept on wearing it and reminding people of that heritage and that identity... to a point where I didn't necessarily have to say I was Filipino for someone to know that I was Filipino. What I mean by that is now that I am in professional spaces, I am able to talk about identity and for them to understand that I speak strongly about 
identity and race and racism, because of my experience as a Filipino person. But I don't necessarily always talk about the Filipino experience, it's just that's the identity now that I bring to the table.

At this point, we see Nathan and the confidence and pride he has in his Filipino cultural identity. In the next passage we see how Nathan begins to connect his experiences and his cultural identity as a Filipino American to the experiences and struggles of other marginalized communities:

And I think in the last ten years, I even moved it away from very strongly wearing and identifying as Filipino to where it just became part of me... whether I wore it from my t-shirt or what not... to in the last 10 years, it even broadened because now I am realizing that the Filipino struggle and the Filipino story-or Filipino-American story-is very similar with many communities and that it's shared...

Armed with critical consciousness, Nathan's counter-narrative begins to describe the fact that he did not see himself present in the dominant discussions on educational leadership pedagogy:

Because when we talk about leadership, there is really - I'm not saying that it didn't exist or it never existed - it's just it's not what we're exposed to, in terms of what the acceptable or what the canon is around leadership. So every time that I read or had been attending professional development or training about leadership-I never saw myself in that until I actually 
either take it upon myself to interject myself there and then I begin to realize, okay, so I really don't see myself here.

A few years ago, having the opportunity to participate in the Association of American Community Colleges (AACC) future leaders institute and having been a graduate of that institute, there were a lot of those experiences in that training-that weeklong training-that really didn't resonate with the way I led myself as a person of color in education. The topics of what leadership is, doesn't necessarily allow us to critique the condition of the institution. And that's the reason why I say I don't find myself, because part of the work I do again is creating and facilitating those spaces to have those hard conversations. But I don't see that in the trainings.

Not only did Nathan not find himself and his experiences within traditional leadership development programs, but Nathan describes the need for educational leaders to be change agents who are not afraid to confront and discuss issues of race and racism in the educational discourse:

I think as educators it's really about being change agents; and when we talk about being change agents it's about also facilitating the dialogue and the discourse on what's difficult. So how do we challenge institutions that 
we work in as educators to really have conversations not just of race, but of racism?

The question Nathan poses is a very important question, but also of importance is the question of how do transformative administrators of color deal with the pressure and the demands of being transformative in addition to their regular leadership roles as administrators.

In this next passage, Nathan discusses the added burden, emotional labor, or third shift that we have previously seen in Sherry and Matthew's counter-narratives. Similar to Sherry and Matthew, Nathan gives his perspective on the social responsibility that comes with being a transformative leader:

Sometimes that's a burden that we really don't want, but then I think it is a privilege to say that "I don't want that". But sometimes you don't have that option. And that's why I am saying, do you fight that or do you just come to terms that that is the social responsibility that you have to act and believe beyond yourself. And I think effective leadership needs to understand that clearly. That when we do things it's not necessarily just because of us, when we do things it's because we are doing it-in education for instance-it's the people that's coming through and relying on you that you're able to give them the experience of development and transformation. 
This sense of the struggle being something bigger than one's self and that their responsibility is one that they owe to their community is an important component to the leadership experiences of transformative leaders of color.

\section{Conclusion}

I presented the counter-narratives of the five middle-managers in this chapter to focus specifically on the development of consciousness among transformative leaders of color. By presenting their stories, I am able to provide examples of the three elements of critical consciousness: (a) awakening, (b) acknowledgement, and (c) connecting. The next chapter will focus on the transformative value of resistance and will present the counter-narratives of four senior level community college administrators of color in order to show how transformative leaders of color contribute to counter-hegemonic resistance and how through their resistance they are able to also engage in a process of healing. 


\section{RESISTANCE: TRANSFORMATIVE LEADERS OF COLOR REFLECT}

Using decolonization and the theoretical works of Franz Fanon (1963), Albert Memmi (1965 \& 2006), Ngugi wa Thiong'o (1986) and Linda Tuhiwai Smith (1999), the transformative value of resistance involves actively challenging and refusing to simply give in to traditional leadership values of authority, power, and control. Resistance involves speaking up and making sure that if an administrator is in a situation where they do not see the experiences of marginalized and oppressed groups being recognized, that they have the responsibility as a transformative leader to serve as an advocate and voice for those communities.

The four counter-narratives in this chapter focus on the stories of the senior-level administrators of color who participated in this study. These stories come from two vice presidents, one president, and one community college district chancellor. In these counter-narratives, we see transformative leaders reflecting and looking back on their leadership careers, how they developed their leadership identities, and the critical experiences which shaped their development as transformative leaders of color.

The first counter-narrative which will be presented is that of Karen. In Karen's counter-narrative, she describes her graduate school experience in which her advisor dismisses her research proposal as not being part of the mainstream and therefore not deemed as worth or belonging in the academy. Given this traumatic experience and the lack of culturally relevant support programs to support her leadership development early 
in her career as an administrator, Karen's counter-narrative focuses on the importance of resistance and the role she now plays in developing transformative leaders among those administrators who she oversees. Andres' counter-narrative will then provide a response to the discussions of emotional labor and the tendency for newer administrators of color to be overly self-critical which Liliana and other newer administrators of color discussed in the previous chapter. Andres' story provides a reflection on how he is able to move past what could be a debilitating obstacle for newer administrators of color and instead is able to reframe the experience to his advantage. This notion of reframing the challenges which administrators of color face into advantages will then be extended in Fred's counter-narrative. In Fred's story, he discusses his experience as a bi-cultural administrator of color and the importance of code-switching as a means of tailoring his leadership approaches based on the particular audience and the situation.

I conclude this chapter on resistance with the counter-narrative of Rebecca. Rebecca's counter-narrative provides examples of how transformative leaders of color can use their critical resistance in order to systematically change institutions such as community colleges to better meet the needs of the diverse student population and as a way to engage in a process of healing.

\section{Counter-Hegemonic Resistance}

The type of counter-hegemonic resistance which transformative leaders of color engage in challenge the hegemonic values, attitudes, beliefs, and morality that has permeated society and has established the status quo (Boggs, 1976; Gramsci, 1971). In 
order to do so, transformative leaders must have critical self-awareness, critical social awareness, and what Gramsci (1971) describes as "active participation in practical life, as constructor, organizer, 'permanent persuader' and not just a simple orator" (p.10). The counter-narratives which follow will show how transformative leaders of color have engaged in counter-hegemonic resistance in their roles as senior-level community college administrators.

\section{Karen Hamamoto}

Karen's counter-narrative as a senior level administrator of color is grounded in the experience of being disregarded, devalued, and not having any social or cultural academic support as she was going through higher education. It was as a graduate student at Boston College where she faced one of her most critical moments:

When I was at Boston College submitting my dissertation proposal to an Irish faculty chair... my topic was a culturally relevant therapeutic model for different cultural communities... now Boston College during that time... this was in the late $80 \mathrm{~s} . .$. I was probably the only grad student who was already teaching there of color of any sort... And then so his reaction in me handing in a 100 page proposal was to say that he couldn't accept it... that this was not a mainstream model and it doesn't belong in academia.

Reflecting back on that experience, Karen goes on to describe the resistance with which she fought to overcome her experience: 
I didn't have social or cultural academic support at that time. It's really only that I think maybe in the mid-90's even in California that I think graduate schools started to have very specific focus on this area of leadership exploration or cultural relevance... we didn't have that until the mid-90's. So I really didn't have any room or luxury to feel the emotional labor. So I just carried it and fought it... fought it... fought it... fought it. Critical to Karen's counter-narrative is the fact that as an Asian American female, her lived experiences, such as the one she endured as a graduate student, shaped the way that she has developed her leadership identity and leadership practice.

For Karen, a key component of her leadership practice is the need to support outof-the-box thinking. As a transformative leader of color, Karen prides herself on encouraging her deans and her staff to challenge current discourse and traditional ways of decision making in order to better serve the needs of marginalized communities and students of color:

But why couldn't we bring the topic that they need to be engaged in... and that's the strength and encouragement we need to ensure that we shift the paradigm there.

She encourages counter-hegemonic resistance by pushing individuals to shift the paradigm so that instead of trying to insert ourselves in the dominant discourse, we shift the discourse all-together to a discourse that acknowledges the experiences of people of color. 
Andres Rodriguez

Andres' counter-narrative revisits the emotional labor, symbolic representation, and overly self-critical tendencies which administrators of color often experience. Similar to the counter-narrative of Liliana, Andres reflects on how his need to overanalyze every decision is not a sign of his insecurities or self-doubt in his ability to be a leader, but instead it is a result of his experience being a member of a marginalized community and the pressures that come along with feeling that you represent more than just yourself when you make a decision:

As a Latino administrator, I think fear of failure and the need to perform beyond the expectation leads you to really really think about everything you are going to do more than other people that I see in administration... so if I'm going to make a decision, I think about it, I ponder it and I ponder it... what could go wrong?... I think I agonize about decisions more than most administrators do.

I think most Latinos-and at least most people of color that I have had the opportunity to work in my leadership capacity-they, like I was, they're so afraid to make a mistake, that they ponder and they think and they reconsider... and I think that we need to eliminate that.

But Andres does also see some positive benefit to the fact that his leadership practice involves critical reflection: 
The most important thing is that you have to be willing to look at what you do and reflect on it... like on your own. So if I make a decision and whether it was in 1980-something or 90 -something or $2000 \ldots$ I make a decision and then I'll think about it and even though the act is finished and something else has taken on a life, I still sit and think of why did I do it, how did I do it, what did I learn from it and then when the situation comes up again or a similar situation, you handle it differently.

It is in finding the balance between engaging in critical reflection and knowing when it is holding you back as an administrator of color that is key to Andres' counter-narrative.

In terms of his consciousness as a transformative leader of color, Andres also sees his leadership identity as being shaped by the intersections of his multiple identities:

I wouldn't just focus what I've done in terms of my leadership development on education... because I think you are a whole person and I think that's something that educators bring when they are from different groups and I think they're not just a manager, they're not just the dean or not just the VP... they bring everything... so I had a lot of opportunities for leadership in religious organizations, in community organizations... even in our families... like in my family, I'm expected to be the responsible one because I'm the one that's best educated or most educated, so even though I'm the third child, I'm still responsible for everything that happens in my parents' household, everything that happens in my 
brother's household... I'm responsible for like five households... so that makes you learn to deal with things and survive... so I think that's part of what helped me to become a leader.

Similar to Tracey's counter-narrative, Andres attributes a large part of his leadership identity and leadership praxis to the importance of family and the values instilled in him through his family, as opposed to accepting the more dominant and traditional leadership qualities of authoritative leadership:

Most of my actions are based on my principles... my values... I always tell myself, "what would my dad do", "what would my uncle do"... the people that I really look up to and respect. And you have to learn that that's ok... not what would Bill Smith do or Joe Jones do... no... what would my dad do because he has very strong values.

In the end, one of the most important messages in Andres' counter-narrative is the need for administrators of color to be confident and comfortable in who they are and their own leadership identity - to reach critical consciousness:

Leadership is about letting who you are come through when you are making decisions and what you stand for... because people respect and people admire and are ok being led by somebody who shares their values. 
People have to know who they are... they have to be confident and comfortable with who they are... and they need to know that their voice is going to make an impact...

\section{Fred Chieu}

As a senior level community college administrator, Fred's counter-narrative focuses on the cultural dichotomy he has often felt as a Chinese American:

Initially, there is the Asian side of you which tends to be more of a quieter, more mellow, more accepting... and then there's the so-called Americanand in this case New York side-which is very over the top, assertive, confident, caulky ... and I guess you just have to meld the two. You understand that you are bi-cultural... you are Chinese-American... AsianAmerican. And then I would observe Asian Americans in leadership places... people like Elaine Kim who is a Berkeley professor, very assertive and charismatic Asian American woman who is very proud of her ethnicity, proud of her culture and yet has embodied a lot of the traditional traits you would expect in leaders in America: self-confident, articulate... again, assertive.

For Fred, there has always been a struggle between finding a balance between his cultural identity and the dominant leadership culture: 
We all have to struggle with our main cultural identity and we have to develop a hybrid that doesn't compartmentalize or subjugate your own Asian identity so as to say that "I have to be white" in order to succeed. In developing the hybrid identity that Fred describes, he gains consciousness and an acknowledgement of the impact that his cultural values and background plays in his overall leadership practice:

We've often heard the term, "you have to out-white the whites" and I think rather, the way to "out-white the whites," or a way to exert your leadership style, is to really understand who you are and what are some of the wonderful attributes of leadership... and I said in my dissertation that more and more of Asian American characteristics are becoming more valued: collaboration, not working from the top down, being more thoughtful, not always speaking just to get airtime... so I think there's a lot to be said for the positive attributes of Asian leadership and the Asian culture as you can infuse that and meld it together with so-called traditional, more American characteristics.

But how does one effectively meld what at times can be two conflicting and polar ways of leading? For Fred, the answer was in mastering the art of code-switching and consciously knowing when to code-switch to his advantage.

An example of Fred's conscious use of code switching was during his interviews for the college presidency: 
I think during the interviews for the presidency, you clearly want to make an impression and leave an impression to the interview committee that you are capable of leading the institution. And I think that you have to "turn it on" at that time... you have to be on your "A-game" so that you don't necessarily have to be a traditional so-called "white president" whatever that is... I mean white folks are just as different as each other. So I think it's more than that. My approach towards the presidential interviews was to really just put out who I am... that I am comfortable in my own skin. And I also put out that I will be a President for all students and all faculty, however, I am also very proud of my Asian American heritage and I think it can be seen as an attribute and a positive in terms of my demeanor and the type of culture or campus climate that I would create... it's not so much Asian... it's multicultural, it's multi-inclusive and it's a safe environment for people to have discourse. So, that was an instance where I really made a conscious effort. You can't hold back and sit back. You really have to show your stuff. And exude confidence, exude a comfortability that this is a good fit between the applicant-in this case myself-and the institution.

In this example, Fred acknowledges that, to a certain degree, he has to exude the type of confidence, assertiveness, and traditional leadership qualities which people will be 
looking for, but he also emphasizes the qualities of his Asian American cultural background which would make him a more effective and well-rounded administrator.

Fred credits his leadership development to the presence of multiple and diverse mentors:

I have mentors who are African-American, who are white, who are women, who are also Asian, but my experience has been-and I would advise others-is that mentors come in all different sizes and shapes and colors. And you don't necessarily need to have only one mentor... I have a whole cabinet full of people who I can call on for different needs. I think that in this day and age, you need to have that kind of breadth of mentors so that you can be well rounded.

Yet while Fred believes that one must have a breadth of mentors from diverse backgrounds and experiences, he, like Tracey, also realizes the value in culturally focused leadership development programs such as LEAP:

LEAP was very culturally specific to Asian Pacific Americans so it dealt with everything from these cultural conflicts, to becoming more assertive, learning how to network, understanding the politics of your higher education on your campus... and most importantly is having sitting president's of Asian descent in the room telling you their story. That I think-to hear Pat Hayashi speak about his experience at UC... to hear Roy Saigo... to hear Bob Suzuki... I mean they are the pioneers and their 
stories would inspire people like me to say "wow... they went through a lot to pave the road for people like me, so therefore now I have to pave the road for the next generation"... But the specific thing that LEAP offers that the other programs don't offer is that it's OURS. It's OUR Asian Pacific American program for Asian Americans... I think it's very powerful to say, "hey, we can do it"... and they ask you to not only do it, but do it well.

As Fred emphasizes the power of culturally focused educational leadership development programs in the above passage, we also get another glimpse into what was described in Nathan's counter-narrative as the greater responsibility of administrators of color not just to themselves, but to the communities and the people that not only came before them, but also the ones that will come after them.

\section{Healing}

In addition to promoting social change, transformative resistance also serves to heal the wounds of alienation and marginalization suffered by those who have been oppressed, as well as the associated guilt that oppressors experience when they awaken to see how they have benefitted from hegemony and social reproduction. In the following passage, Strobel (2001) describes the healing qualities of decolonization among post1965 Filipino Americans:

Decolonization strengthens the cultural connection to the Filipino indigenous culture because it is a source of grounding. The decolonized 
consciousness feels deeply the spiritual connection to one's kapwa (fellow beings), making it possible to identify with one's people and history in spite of personal, generational, educational, economic, class, and other forms of differences... (p.118)

Key to the element of healing as part of transformative resistance is the belief that simply getting rid of oppression in its many forms in simply not enough. Transformative educational leadership pedagogy must also address the scars and wounds that have been left by the various forms of oppression in order to facilitate a process of healing. For transformative leaders of color, this means leading dialogue as well as creating spaces and programs at their institutions where the process of healing is nurtured as a critical component of the resistance process.

\section{Rebecca Pacheco}

Rebecca's counter-narrative is unique in that of all the counter-narratives that are presented in this study, Rebecca, at the time of her interview, was the most senior level community college administrator who participated in the study. Serving as chancellor and chief executive officer of a two-college district, Rebecca's counter-narrative also reveals an emotional and psychological side of being a transformative leader of color because of that fact that, in her own words, Rebecca believes she has been targeted and "taken out" for funding her values and her commitment to issues of social justice and equity for marginalized and oppressed communities. 
Despite feeling as if she was being targeted for her transformative leadership values, Rebecca embodies a particularly strong and unwavering sense of consciousness which lies at the very core of her counter-narrative:

I've said two things. You have to know what you stand for... once you know what you stand for, as you move into administration, your principles and ethical commitment has to be... the behavior that follows... has to be to hire and to fund according to those values and principles. There's no excuse... once you have consciousness. If you're using Critical Race Theory, if you're using some of these good lessons around the system that we've learned, you have an ob-[ligation], you cannot live with yourself because you are now anointed as a critical thinker with an analytical mind that's based in good understanding of power and race in this country. So therefore, every time you give into that because of fear, you hate yourself. So I have... I, because I started so young in my path with Ethnic Studies and being involved in these programs... and actually as I started as a community activist... I've had this consciousness since my teens and it's only gotten stronger and so you know it was only going to take a matter of time... The miracle about me is I've lasted as long as I have without getting attacked. I was... I have fundamentally been taken out for funding my values. 
Critical to Rebecca's transformative leadership is the fact that despite the realization that she knew she would be a target and that "it was only going to take a matter of time" before she would be taken down, she chose to still stay true to her values and engage in critical resistance. When asked how and why she has chosen to commit herself to transformative work:

How do I NOT do it? HOW DO I NOT DO IT? Because I refuse to get co-opted... that's why. I will not allow myself to intuitively get filled with self-hatred... because that's what is going to happen to me and I could destroy myself with that level of shame and feelings of betrayal because I refuse to pick up a book... or I refuse to be engaged in critical dialogue. I don't know how to not be engaged in critical dialogue... it is a part of my honor.

Also an important aspect of Rebecca's counter-narrative is her steadfast belief in holding members of the dominant society accountable for learning about and being committed to issues of social justice and equity:

It's intentional at times, and sometimes it's not intentional. I've seen it be unintentional, however, I have stopped being forgiving with unintentional predators... with unintentional abusers. Because there is too much information available... and there are too many of us who present opportunities for everyone to shift their thinking now. So I blame those who say 'I didn't know' because you could have wanted to enough to pick 
up the same damn books that I have... that you have... Why aren't you reading Yosso in California Today? Why aren't you? You tell me you don't know. Don't tell me you don't know. You don't want to know. It's the same excuse that I say when people tell me that... you know, and this is very relevant to your paper... when people have told me over the years... 'I can't... I don't hire enough diversity because I can't find candidates of color that are diverse'. And I have said for years, 'Gee, I don't have that problem'.

For Rebecca, it is not just the role and responsibility of administrators of color to challenge the dominant discourse, it is the role and responsibility of even those who are part of the dominant discourse to challenge themselves, because as she points out: True commitment changes what you see in the world... if you are truly committed, your intuition, your eyes... you open up differently... if you are truly committed to diversity you see things differently.

It is in this different way of viewing leadership, that Rebecca's counter-narrative gives voice and recognition to the experiences of administrators of color.

Rebecca's critical perspective has been shaped by elements of Critical Race Theory (CRT):

CRT has given us a different level of tools of survival... and tools to do our work because the counter-narratives keep you, in my opinion, from hurting yourself... I've seen too many administrators of color who without 
counter-narratives, without counter-stories, do blame themselves... do question their values... question their sanity... and wind up in very selfdestructive behaviors. I see self-destructive behaviors and the counternarratives are medicine.

Rebecca even shares the importance of being able to tell one's story as a way to heal from the scars and wounds left by abuse and oppression through her own personal experience:

You carry it inside... and you carry shame and guilt and confusion. So... you know, I have always taught my children... well, I want to train the next gen-[eration]... this new generation of leaders to be aware that their abuse was not their fault and it can be... if they've been quiet about it.. and not heal from it... it can be restimulated. And to have that knowledge in their brain so that they remember they heard from me and from other wiser women and experienced people... and this is for both men and women... if you've ever had that kind of pain, when you are restimulated, this is what you do to stay healthy and feel safe. And if you need to withdraw for a while, be kind with yourself and be loving... get healing... because you will be restimulated. Why didn't anybody talk about that... I didn't know, so I went through all kinds of hell in the beginning... in addition to which, I'm a mother, and my children got targeted. So again... once again, it's one thing to have me going... what do you do when they 
go after your children? And so, you know... and... and... I haven't... you know... nobody's known that... you know... but... so how do you... so but, you know what the interesting thing is I've got... I understand now... I understand how to protect... so I need to teach to it... but I need to be allowed in the academy... I need space.

As difficult as her own personal experience has been, the part of Rebecca's counternarrative that is so revealing of her transformative educational leadership pedagogy and praxis is the fact that she still feel compelled to teach it, to teach future generations of administrators of color to learn from her experience and the need to create spaces where these experiences can be shared and taught.

\section{Conclusion}

In the counter-narratives of the four senior-level community college administrators of color which have been presented in this chapter, we are able to see the continued development of consciousness among the transformative leaders, but we also begin to see specific examples of counter-hegemonic resistance and the healing qualities which administrators experience as part of their work as transformative leaders of color. In the next chapter, the final value of praxis and its role in supporting a transformative educational leadership pedagogy will be discussed. 


\section{PRAXIS: DEVELOPING A TRANSFORMATIVE EDUCATIONAL LEADERSHIP}

\section{PEDAGOGY}

The final component of praxis refers to the Freirean belief that human activity must involve both reflection and action:

But human activity consists of action and reflection: it is praxis; it is transformation of the world. And as praxis it requires theory to illuminate it. Human activity is theory and practice; it is reflection and action. It cannot, as I stressed in Chapter 2, be reduced to either verbalism or activism. (Freire, 1970, p.125)

For transformative educational leadership pedagogy, praxis, and the importance of both reflection and action, is critical to addressing the needs of students. Simply knowing that social conditions and pedagogical challenges exist (reflection) yet not doing anything about it (no action) is inadequate for transformative educational leaders. Yet just as inadequate, and more so irresponsible, would be establishing programs and services to "remediate" underachieving youth (action) without first properly understanding and acknowledging the social conditions that have led to underachievement (no reflection).

\section{Humanization}

Humanization, as a component of praxis, becomes a transformative leader of color's ability to understand and address the holistic needs of the students they serve. It involves the type of authentic caring that Valenzuela (1999) describes in her book on 
U.S.-Mexican youth. As we will see in Rochelle's counter-narrative, humanization and acknowledging the importance of peoples' life stories becomes an important component of how she ultimately defines her transformative leadership framework as "leading to transgress".

Rochelle Simpson

Rochelle's counter-narrative focuses on the importance of culturally focused educational leadership development programs, the emotional and psychological impact of systemic and historical oppression on administrators of color, and the importance of our stories and the use of counter-narrative to validate the experiences of administrators of color. As one of five senior level administrators of color in this study, Rochelle's counter-narrative is valuable in documenting the "non-traditional" trajectory which has led her to her current leadership position:

As you are in different leadership positions, you develop additional skills and talents... and you develop the capacity or the ability to move up and to make a greater contribution and to take a greater responsibility... or to influence the institution in a more broader, much higher level. So in a traditional institution of higher ed, there's kind of a traditional trajectory that you go through... So there's a traditional trajectory, but particularly for people of color, that trajectory is not always that. And there's some real implications for that. 
In particular, Rochelle's counter-narrative takes her from her start as a career in the healthcare profession to becoming a community college faculty member by virtue of an instructor suffering an accident and her having to take over for the course.

Along the way, Rochelle also had the opportunity to serve as the president of the statewide academic senate:

It [experience as statewide academic senate president] developed me in terms of being able to navigate the systems and navigate agencies... I might have to do anything from make a recommendation to the Board of Governors as to the results of the plenary session to testify on behalf of the faculty or the system to the senate appropriations committee. It just exposed you to different experiences and challenges.

Rochelle's attributes her role as statewide academic senate president as having a direct impact on her overall leadership development:

And that was key and critical in my leadership development because it required me to develop political savvy... where I learned it wasn't just enough to be right.

This is also where Rochelle, similar to Fred, consciously uses the notion of code-shifting in order to cater her leadership style depending on the audience and situation:

It's code shifting... so I don't think that you have to decide that this is the way that I'm going to be as a leader or this is how I am going to be as a 
leader. I think you go in and out of different ways of leading... you know, in and out of different contexts in a regular basis.

Conscious of the different roles and expectations that are placed upon her as a leader and administrator of color, Rochelle is able to tailor her responses through code-shifting. In terms of Rochelle's experience with traditional professional development and mentorship programs, she struggled in her earlier years to find a program which she could connect to:

I searched very specifically for a leadership institute that would help me because I struggled... to be honest, I started as an ACCCA mentee, but I have the dubious distinction of being an ACCCA mentee dropout because I didn't want to establish or identify administration as my goal and their goal was to increase administrators. But I also was frustrated in that I had a mentor assigned to me that I could not necessarily connect to... and it had a lot to do with this person having a very different experience than mine. So this very nice, but very white, blonde woman who could not relate to my experience at all and would provide leadership advice that did not validate or identify or even acknowledge the kinds of milieu that I had to navigate as an African American woman.

Later on, she was able to participate in the Thomas Lakin Institute for Mentored Leadership in which she had a completely different experience: 
It is an institute that is specifically targeted at developing African American leaders and helping African American leaders understand some of the issues that they will deal with in leadership positions in these community colleges as African Americans and that was one of the most effective, richest experiences that I had... It was a typical leadership institute, the difference was that there were affirmative steps for bringing to bear issues that you deal with as an African American... and people who were in leadership positions that knew exactly what you meant when you said what you said or when you talked about a situation that occurred. Rochelle's experience, similar to those of Tracey and Fred, provides another example of the importance of culturally focused professional development and educational leadership development programs.

Rochelle's counter-narrative also provides a vivid example of the types of issues that African American administrators have to face which are not recognized or discussed in the traditional leadership discourse:

You end up having additional duties... let's say you are dealing with the stressors of the institution... and let's say you're having the meetings and you're dealing with whatever the issue is... let's say the budget crisis or whatever... and when you come in for those things, we got regular stuff... the refreshments are out... we got cookies... we got water... coffee and fruit... Alright, so most people get to come in that room and say, "Oh 
neat, oh refreshments... good, I think I'll have some." And they can just put anything they want on their plate... But I believe, and I don't think it's all, but I believe that part of the narrative that goes on in some African American peoples' minds... particularly in leadership positions, is when they come into that room and they pick up the refreshments, they CANNOT pick up the watermelon. They can't pick up the watermelon first, or they gotta be conscious about thinking about it. They gotta make sure that they have a significant mix... "or maybe if I just get the melon balls and not the melon slice"... they gotta put energy into that because they also, aside from the budget situation, they have to make sure that they don't validate negative stereotypes... because many of them may have come from positions and walks of life where their families have taught them the responsibility they have to represent their race well. Because what you do out there is not really about you, it is about you working for the benefit of your people. So in the meantime, everyone else can get their refreshments and sit down... so if you're going through that narrative about oh, the watermelon and... it's quick and it's short... it's these micro-moments... but it still is these racialized moments that you have to go through.

Rochelle's example is an authentic depiction of the type of daily situations where for transformative leaders of color, issues of race and the systemic and institutionalized 
effects of racism and oppression continue to impact their experiences and decisionmaking processes.

As an administrator of color, Rochelle is conscious of the social responsibility that comes with being in an administrative position:

I describe my leadership framework as leading to transgress and that basically is something that is... something that I have identified as a way of trying to overcome... to lead to influence the allocation of resources and to influence the ways in which we can overcome some of these systems of oppression and domination... that we can influence some of these structures within these institutions of higher education... and so it's transgressing those system of racism and sexism and all other types of systems of oppression and domination. But that framework is allencompassing and it requires lots of different tools and lots of different ways of being and knowing.

One of the tools that Rochelle uses to transgress and consciously engage in critical resistance is by acknowledging the importance that our life stories bring to our overall leadership practice:

I believe that we bring to bear our life story and what we've learned in life... and our responsibility is to represent the race as African American women particularly, or as people of color... we bring those to bear to 
navigate these institutions and these power dynamics that are in these institutions in order to lead to transgress.

When we bring to bear our life experiences, then we have additional dimensions that inform our experiences... that inform our decisions... and we also have the ability or the capacity to understand that the students then come with their own stories... with their own hardships... regardless of how they present... whether they're white students or poor students or whether they're student of color... or Asian Pacific Islander... they come with their own stories and so it's taught me to not be so fast and careless with the scripted answer for whatever the policy or issue to a decision might be. To recognize that these are real lives, particularly in these times. That these are real lives, these are individual lives and while it might be alright in terms of the overall numbers of FTES that's impacted, there's one individual where you're making the fundamental difference... and it's not just in their life... it's in their family's life... and it's not just in their family's life... it then means in the community's life. And so it makes me be careful and not be fast.

Here, we see the recurring realization among transformative community college administrators of color about the impact which decisions and leadership practices have 
not just for the individual students with which we interact with, but the impact that those decisions and practices have for the overall communities that we live in and belong to.

\section{Humility}

By continuously engaging in praxis, transformative leaders also embody a level of humility. Humility is needed in order to continuously reflect on one's own actions and realize that at the same time that one can see themselves as part of the oppressed, they are still benefitting and operating as part of an inherently oppressive educational system.

Freire further expands on the importance of humility as a component of transformative educational leadership pedagogy with the following passage:

Men and women who lack humility (or have lost it) cannot come to the people, cannot be their partners in naming the world. Someone who cannot acknowledge himself to be as mortal as everyone else still has a long way to go before he can reach the point of encounter. (p.90)

To this effect, educational leaders must practice humility and not assume "paternalistic" or "savior" roles, for as Freire (1970) cautions, "They must not forget that their fundamental objective is to fight alongside the people for the recovery of people's stolen humanity, not to 'win the people over' to their side" (p. 94).

\section{Liliana Revisited}

While Liliana may still have been engaging in a process of developing consciousness as a young transformative leader of color, we are already able to see the 
importance and value of critical reflection emerging as a tool that grounds Liliana's leadership praxis:

Being very new to it, I did question myself, so then it was the reflecting to help me say, wait a minute, you've only been here two months, this is a brand new job... and I have the skills... and I am equipped to do it... and it's just a matter that it's going to take time... and it's also... I think the reflection is good because it allows us to be able to say... it's okay if you don't finish it, but I think it goes back to that initial concept of having to prove yourself all the time.

This critical role of reflection which Liliana's has developed as part of her leadership praxis is a component of transformative educational leadership pedagogy that will accompany her throughout her entire career as a transformative leader of color.

\section{Nathan Revisited}

Also incorporated into Nathan's praxis is a sense of humility and a sense that he must always remain grounded in the needs of the community-no matter how high of an administrative position he may reach:

Even the most critical reflective individual needs to also realize that there might be something that they haven't even realized that they have as a level of privilege that the community that they are working with doesn't have. Just the fact that you need to embrace the fact that there is a difference and separation is already a critical move for administrators, but 
how often do we do that vs. imposing our own privileges. I think we do that more than we are reflective.

Nathan further defines his praxis as an ongoing learning process by stating: I think it becomes an ongoing learning process where you look at the traditional notion of what leadership is and for me I only use that information and the knowledge of what traditional leadership is to critique the environment whether it was traditional and just to be able to analyze what it is but I wouldn't necessarily say that I was cognizant of what I was practicing was traditional or was the alternative or progressive or radical or however you are willing to label that. I just felt like I was just carrying me. Everybody knew from the interview of getting the job to until leaving the job that this is my philosophy.

Here we are able to see how as a transformative leader of color, Nathan's commitment is less focused on the "label" or the naming of his leadership style as "transformative," but instead his focus is on ensuring that his everyday actions remain true to his transformative leadership identity.

\section{Karen Revisited}

An important aspect of Karen's praxis is her focus on reflection and the role which reflection plays in her ability to have a strong sense of self:

On my long commute back every day I think about those things so I think you need to really unpack what you have done and how you have done 
things and really sort of like look within and really being able to name your own experiences. I think that is really important.

For Karen, reflection is a daily and ongoing process that may not necessarily lead her to perfect answers or greater clarity, but that the process itself of self-reflection allows her to view things from multiple perspectives:

When I talk about self-reflection of any sort, I try to own whatever I am engaged in and whatever I am thinking about and I not always have answers, but I think it is really important for me to challenge myself.

Through the process of self-reflection, Karen's praxis as a transformative leader continually challenges her own set of biases and beliefs. Similar to Nathan's counternarrative, Karen's self reflection and praxis is informed with the belief that leadership pedagogy is an ongoing learning process and that there needs to be a certain level of humility present in the praxis of transformative educational leaders so as to be open to the fact that one not always may have the answer.

Karen's counter-narrative also focuses on the importance of being able to tell each others' stories:

Really talking stories... spending time and talking stories... that's where we gain a lot of information and we get empowered. But if that is taken away, of course we are going to feel insecure and disconnected and then we feel like we have to find other ways to augment that. But why can't we simply bring that important time back into our learning process. 
Presenting Karen's counter-narrative as part of this study, hopefully serves as a way to bring back that important time she refers to and incorporate it into the learning process. Fred Revisited

Similar to Liliana, Nathan and Karen, Fred's praxis incorporates a sense of humility and "work in progress" attitude towards his leadership pedagogy:

If you want to be a leader, most leaders I've seen are never complacent... they never feel like they've arrived... they're always works in progress. At least that's how I feel. So I think that you take that type of attitude. As one of my mentors said, "you have to know what you don't know," and nobody knows everything... and if you want to get better, you have to be willing to change up. And so as much as I have accomplished in my professional career, I always bring with it a sense of discovery, a sense of humility, a sense of... I can always learn. And it doesn't have to be from another leader... it can be from a student... it can be from a custodian... it can be from all walks of life... it can be from a senior citizen with a tremendous amount of wisdom. So I think what I look at is there are always opportunities to lead, and there are always opportunities to learn more about how to lead more effectively.

By taking this approach, Fred is constantly trying to make sure that he is able to connect to students and the concerns of their generation: 
I think one of the challenges I find in community colleges is generational leadership. The type of Generation X, Generation Y, you know... we're all looking at different approaches and views of the world... so I often times talk to young people-like my nephews-and see how they view the world... it's very different then when we were growing up... so I think that's something I stay on top of because ultimately it will impact learning styles, it'll impact how information is processed... and I think where were stuck in our educational system is that we are looking at using traditionalthree generations ago-how to teach something that is in many ways irrelevant and not "cool" or not timely... it's not going to resonate with this generation... My approach has always been: how do I communicate to my constituent groups in a way that they are comfortable with. And I don't know if all leaders understand that piece of it.

Fred's focus on connecting to the experiences of his constituents is perhaps one of the most salient and profound aspects of his counter-narrative. Fred shows us that as leaders, our responsibilities are not to know what's best and make decisions for our constituents, but instead our role is to listen and hear from our constituents in order to be their advocates and voices.

\section{Conclusion}

In this chapter on praxis, the importance of developing a transformative educational leadership pedagogy which is grounded in both reflection and action is 
conveyed through the counter-narrative of Rochelle and a revisiting of several of the transformative leaders of color whose counter-narratives were presented in earlier chapters. Two important components of transformative praxis are humanization-the ability of leaders to connect and relate to students on a personal, holistic, and human level, and humility-the necessity for leaders to continuously reflect and realize that their role is to fight alongside the people for the recovery of people's stolen humanity (Freire, 1970).

The final chapter will bring together the emerging themes from the last three chapters which have focused on providing counter-narratives of consciousness, resistance, and praxis. I will also conclude with a set of four recommendations which can be implemented to support the further development of transformative leaders of color. 


\section{DISCUSSION AND RECOMMENDATIONS}

Now that you have had the opportunity to read the counter-narratives of the eleven administrators of color who participated in this study, I present a synthesis of the relevant themes which have emerged from their stories. Using the three values of transformative educational leadership - consciousness, resistance, and praxis - I organize the emerging themes according to these three elements and then provide four specific recommendations which can be used to support the development of transformative leaders of color. I will conclude by summarizing the implications of this dissertation to the field of educational leadership and the possibilities for further research.

\section{Consciousness}

One of the main themes which emerged from the counter-narratives, especially as it relates to the early stages of an administrator of color's development as a transformative leader, is the need to deal with and overcome feelings of being an outsider and being different from the dominant group. As we saw with Liliana, Tracey, and Sherry, all three described this experience as feeling like they needed to prove themselves and that there was a double standard by which administrators of color were held to in comparison to their white male counterparts. In Liliana and Sherry's experiences in particular, and as we see also see addressed in Andres' counter-narrative, the need to prove one's self and be overly critical leads to some administrators of color going back and forth, over and over in their head, before actually making a decision. While this can 
appear on the surface to be a lack of self-confidence on the part of the leader, especially if we were to analyze the experience through traditional leadership values of authority, power, and control, analyzing the experience through a transformative model instead reveals the administrator of color's development towards consciousness.

In addition, Freire suggests that it is the discomfort caused by feeling different and feeling like an outsider that will ultimately lead the administrators of color to the point of awakening. Several of the administrators point to their undergraduate experiences and their experiences with ethnic studies programs while they were in college as the initial spark which triggered the awakening process.

Also a component of critical consciousness is the acknowledgement that one's ethnic and cultural background is an important part of one's leadership identity. We are able to see the acknowledgement process from Tracey's counter-narrative, as she describes how her participation in a summer professional development program allowed her to recognize, acknowledge, and be okay with the fact that her Asian American cultural values play a role in shaping her overall leadership identity. For many, as we see with Sherry, acknowledgement is also a very emotional and psychologically demanding process as administrators feel lonely and isolated going through the process. For others, like Miguel and Nathan, overcoming the loneliness and isolation which accompanies acknowledgement leads them to a strong conviction and pride in their cultural background. 
Connecting is a critical component to consciousness because it is through connecting that transformative educational leaders move from the personal to the collective. While awakening and acknowledgement are somewhat individual and personal processes, it is through the process of connecting that transformative leaders of color begin to see how their experiences are part of a larger struggle faced by other marginalized and oppressed communities. Connecting also means bringing together and realizing how one's multiple identities intersect and interact with each other in order to develop an overall leadership identity. This notion of the intersection of multiple identities and the importance of connecting was most evident in Matthew's counternarrative.

Another component to connecting is the importance of having allies and building alliances. In several of the counter-narratives, administrators of color cited the role of allies as integral in providing them with crucial support and encouragement, especially during difficult times. Allies become resources that administrators of color can go to and call upon whenever they need a second opinion or just need to vent.

Grounding the importance of consciousness to the theoretical framework of CRT, consciousness becomes the way through which a transformative leader of realizes the intersectionality of racism, classism, sexism and other forms of oppression. As Rebecca pointed out in her counter-narrative, once armed with critical consciousness, it then becomes the duty and responsibility of the transformative leader to actively engage in forms of resistance. 


\section{Resistance}

Having grounded the transformative value of resistance in the theoretical framework of decolonization, resistance is rooted in a leader of color doing away with the colonized individual he has become (Memmi, 1965). As we see in the counter-narratives of Karen, Andres, and Fred, this critical resistance involves not only having people of color gain access into leadership positions, but it means shifting the very way that institutions operate so that they are more responsive to the needs of marginalized and oppressed communities.

As we saw in both Fred and Rochelle's counter-narratives, resistance also involves the ability to code-switch and to know when and where leaders must balance the use of traditional leadership values of authority, power, and control as they engage in transformative resistance. This connects back to what Weiner (2003) described as the problematic situation for transformative leaders of engaging in resistance and being transformative while still keeping one foot in the dominant structures of power and authority that they are trying to change.

Without a transformative model to analyze resistance as a leadership value, it would be very difficult to acknowledge and recognize the important work that transformative leaders do to try and change educational systems so that they better meet the needs of an increasingly diverse student population. As it currently is, transformative leaders see a lot of their social justice work as an "added responsibility" that they have on top of their traditional leadership responsibilities. 
Praxis

As the last of the three transformative values that I have presented, praxis is an essential component for transformative leadership pedagogy. The very definition of praxis as the result of both reflection and action challenges traditional authoritarian leadership values which would argue that the role of the leader is to tell their subjects what to do and that the role of the subordinate is to simply follow the leader's orders without question. Engaging in praxis is what guides transformative leaders in their work towards what Freire (1970) describes as authentic liberation.

We begin to see the importance of praxis even in the early stages of a leader's transformative leadership development process. In Liliana and Karen's counternarratives, they note the importance of self-reflection and the need for leaders to spend the time to reflect as part of their leadership praxis. Nathan and Fred extend the importance of praxis as a way of remaining humble and grounded to the communities they serve.

Challenging traditional leadership values which would promote assertiveness, confidence, and "leader as expert", praxis as a transformative leadership value promotes a level of humility in which leaders like Fred realize that they can never view themselves as knowing everything that they need know in order to be an effective leader. Humility also involves a transformative leader's recognition that they benefit from a certain level of privilege by the very virtue of being in the leadership position that they occupy. Humility becomes the distinguishing factor by which transformative leaders fight 
alongside oppressed and marginalized communities as opposed to taking on more savior and paternalistic attitudes towards the communities they serve. As Freire (1970) states, "They must not forget that their fundamental objective is to fight alongside the people for the recovery of people's stolen humanity, not to 'win the people over' to their side" (p.94).

Recommendations to Support the Development of Consciousness, Resistance, and Praxis in Transformative Leaders of Color

Having presented the relevant themes which have emerged from the counternarratives of the eleven administrators of color who participated in this study, I now present a set of four recommendations which can be used to support the development of transformative leaders.

In presenting these recommendations, the objective is not to produce a certain level of transformative leader. What I have tried to articulate through the counternarratives are the varying levels and wide spectrum which exist when it comes to the passion, intensity, and commitment to transformative work that each of the leaders practice. My intention in presenting their counter-narratives is not to establish certain standards or thresholds to hold transformative leaders to, but instead to provide examples of different ways that leaders do transformative work within their role as community college administrators. The recommendations that I present are designed to support the development of transformative leaders by providing environments where transformative leadership practices can be acknowledged, validated, and recognized. 


\section{Recommendation 1:}

Increase the use and inclusion of counter-narratives in educational leadership literature and research.

In the review of community college organizational culture and change presented in chapter two, Levin (1998) described how organizational change in the community college was conveyed through storytelling and that it was through the telling of stories that individuals made sense of the organization and its relationship to its environment. The struggle for administrators of color, as we see in the counter-narratives of Karen, Nathan, Rochelle, Rebecca, and many of the other administrators is the fact that their stories as administrators of color were not being told.

This first recommendation advocates for the greater use of counter-narratives in educational leadership literature and research so as to make sure that the experiences of administrators of color become a part of the regular discourse. As Solorzano and Yosso (2001) point out, there are four specific contributions which counter-narratives can make to the literature and research on educational leadership: (a) build community among those at the margins of society by putting a human and familiar face to educational theory and practice; (b) challenge the perceived wisdom of those at society' s center by providing a context to understand and transform established belief systems; (c) open new windows into the reality of those at the margins of society by showing the possibilities beyond the ones they live and demonstrating that they are not alone in their position; and (d) teach 
others that by combining elements from both the story and the current reality, one can construct another world that is richer than either the story or the reality alone.

We see examples of each of these four contributions in the counter-narratives that have been presented. In particular, Karen summarized the importance of being able to tell her story: "Really talking stories... spending time and talking stories... that's where we gain a lot of information and we get empowered. But if that is taken away, of course we are going to feel insecure and disconnected..." In relating the importance of counternarratives to developing an administrator of color's leadership pedagogy, Rochelle states:

When we bring to bear our life experiences, then we have additional dimensions that inform our experiences... that inform our decisions... and we also have the ability or the capacity to understand that the students then come with their own stories... with their own hardships...

By acknowledging their counter-narratives, administrators of color also have an opportunity to engage in the same type of healing process which Strobel (2001) describes in her discussion of the decolonization process among post-1965 Filipino Americans. In Rebecca's counter-narrative, she shared the importance of being able to tell her story as a way to heal from the scars and wounds left by abuse and oppression.

\section{Recommendation 2:}

Support the further development of culturally relevant leadership development programs such as those offered by APAHE (Asian Pacific Americans in Higher Education)/LEAP (Leadership Education for Asia Pacifics) and the Thomas Lakin Institute. 
Through the experiences of Tracey, Fred, and Rochelle, we see the important value in culturally relevant leadership development programs to the transformative leadership development of administrators of color. This recommendation supports the further development of such programs so that they are more widely available to both new and seasoned leaders.

Culturally relevant leadership development programs support administrators of color in developing a critical consciousness by focusing on the acknowledgement aspect of consciousness. As Tracey pointed out: "I think what's really been the most valuable was just understanding where you came from and what components of you do you need to have in order for you to be at your best and your strongest." It is through these types of programs that administrators of color are able to openly discuss and come to terms with how their cultural values may be in conflict with some of the more dominant expectations of leadership such as assertiveness and strict authoritarian practices.

In his description of the role that the LEAP/APAHE program had on his leadership development, Fred captures the essence of what sets these prograrns apart from traditional leadership development programs: "the specific thing that LEAP offers that the other programs don't offer is that it's OURS. It's OUR Asian Pacific American program for Asian Americans." It is through these types of programs which bring together a politically engaged community of practice that we are able to operationalize what Huiskamp (2002) and Lave and Wenger (1991) describe as the decolonization of traditional systems of leadership. 


\section{Recommendation 3:}

Provide both formal and informal opportunities for administrators of color to connect with colleagues through culturally-focused networking and mentorship opportunities.

In addition to the formal leadership development programs addressed in the previous recommendation, this recommendation advocates the creation of both formal and informal opportunities for administrators of color to connect with colleagues who have shared experiences. Through these networking and mentorship opportunities, administrators of color would have access to each other so that they can share stories and, more importantly, have people who they can go to when they are going through particularly difficult situations in their career. As we saw in Sherry's counter-narrative:

There would be times where I would go back to my office and cry... and I would let my boss know what was happening... not get any real support or affirmation from him... just like "wow, that's tough"... and that was pretty lonely... and I remember feeling like I was so different from him. There was no common ground.

Having formal and informal opportunities for administrators of color to develop alliances and networks would not have made this experience so lonely for Sherry because she would have had people who she could have called on and vent to.

Rochelle's counter-narrative also stresses the importance of culturally focused mentorship opportunities. While Fred articulated the importance of having a wide variety of mentors from across different cultural and ethnic backgrounds so as to provide an 
administrator with a breadth of knowledge and experiences to learn from, Rochelle points out how she was in need of a mentor who she could actually connect and relate to:

But I also was frustrated in that I had a mentor assigned to me that I could not necessarily connect to... and it had a lot to do with this person having a very different experience than mine. So this very nice, but very white, blonde woman who could not relate to my experience at all and would provide leadership advice that did not validate or identify or even acknowledge the kinds of milieu that I had to navigate as an African American woman.

Given the culturally-focused nature of the recommendation being presented, I feel it necessary to provide a disclaimer at this point. In my previous experience, a common criticism of advocates for culturally-focused programs and services is that we are merely promoting separatism and further marginalization of our communities from the mainstream culture. What I would like to point out is that in advocating for culturallyfocused programs and networking opportunities, the objective is to simply provide opportunities and spaces where administrators of color can feel safe in sharing their experiences with those who understand and can relate to them because they have gone through similar experiences themselves.

\section{Recommendation 4:}

Include ways of recognizing and documenting transformative leadership contributions as part of the administrative evaluation process. 
This recommendation specifically addresses the need to include an administrator's resistance and contributions towards transformative pedagogy as part of the administrative evaluation process. By institutionalizing transformative pedagogy as an expectation of all administrators, social justice work will no longer be viewed as an option, but as a requirement that is needed in order to ensure that our educational systems are adequately serving the needs of all students.

Of the four recommendations being presented, this final recommendation addresses the need for educational leadership pedagogy to incorporate transformative leadership values as part of the general expectation for all administrators. As we have seen in several of the counter-narratives, administrators of color who are involved in doing transformative work often view this work as needing to go "above and beyond" what is expected of them as an educational administrator. If transformative leadership is grounded in systematically analyzing schools and confronting inequities regarding race, class, gender, language, ability, and/or sexual orientation (Cooper, 2009), then why should it be viewed as something which leaders do above and beyond of their normal responsibilities? In order to really shift the paradigm of educational leadership pedagogy so that transformative leadership values become part of the dominant discourse, transformative work must become an expectation we have of all administrators.

By including ways of documenting and assessing for transformative values in the administrative evaluation process, organizations can institutionalize their commitment to transformative pedagogies and serving the needs of all students. For Miguel, this would 
significantly change how he currently views his commitment to advocating for undocumented students as being rooted solely in his personal values with a clear lack of any institutional support or encouragement.

Implications and Possibilities for Future Research

While this dissertation has focused on the leadership experiences of community college administrators of color in order to establish a model for transformative leadership which focuses on consciousness, resistance, and praxis as its leadership values, the model has overall implications to the broader field of educational leadership in general. In addition to giving value, acknowledgement, and honor to the experiences of the community college administrators of color who shared their counter-narratives, the recommendations which are presented in this chapter are aimed at developing ways to encourage and support the continued development of transformative leaders.

Using the transformative values of consciousness, resistance, and praxis, this dissertation has provided a unique analysis of the leadership experiences of administrators of color which shifts the analysis from more traditional leadership values of authority, power, and control. While traditional leadership models will continue to exist and shape the leadership expectations of administrators, it is hoped that the attempt of this dissertation to shift the discourse to a more transformative model will encourage future literature and research on educational leadership to recognize transformative values of consciousness, resistance, and praxis as legitimate leadership values which can be used to better understand the leadership experiences of transformative leaders of color. 


\section{REFERENCES}

Bass, B. M, (1985). Leadership and Performance. New York: Free Press.

Bass, B. M. (1998). Transformational leadership: Industrial, military, and educational impact. Mahwah, NJ: Erlbaum.

Boggs, C. (1976). Gramsci's Marxism. London: Pluto Press.

Bishop, R., O’Sullivan, D., \& Berryman, M. (2009). Scaling Up Education Reform: Addressing the Politics of Disparity. Wellington, New Zealand: NZCER Press.

Blackmore, J. (2006a). Deconstructing diversity discourses in the field of educational management and leadership. Educational Management Administration \& Leadership, 34(2), 181-199.

Blackmore, J. (2006b). Social justice and the study and practice of leadership in education: a feminist history. Journal of Educational Administration \& History, $38(2), 185-200$.

Blake, E. (2007). The emotional labour of critical pedagogy: an autoethnographic study of teacher identity. M.Ed. dissertation, University of Prince Edward Island (Canada), Canada. (Publication No. AAT MR22817).

Bolton, M.K. (2000). The Third Shift: Managing Hard Choices in Our Careers, Homes, and Lives as Women. San Francisco: Jossey-Bass.

Brown, K. M. (2004). Leadership for social justice and equity: Weaving a transformative framework and pedagogy. Education Administration Quarterly, 40(1), 77-108. 
Buenavista, T., Jayakumar, U., \& Misa-Escalante, K. (2009). Contextualizing Asian American education through critical race theory: An example of U.S. Pilipino college student experiences. New Directions for Institutional Research, 2009(142), 69-81.

Burns, J.M. (1978) Leadership. New York. Harper \& Row.

Cambron-McCabe, N., \& McCarthy, M. (2005). Educating school leaders for social justice. Educational Policy, 19(1), 201-222.

Chou, R. (1992). Keynote Speech Comments by Rebecca Chou in Chinese for Affirmative Action, Report of CAA $3^{\text {rd }}$ Upward Mobility Conference. San Francisco: Chinese for Affirmative Action.

Chua, P., \& Fujino, D.C. (1999). Negotiating new Asian-American masculinities: attitudes and gender expectations. The Journal of Men's Studies, 7(3), 391-413.

Collins, J. (2001). Good to Great: Why Some Companies Make the Leap and Other's Don't. New York: Harper Business.

Committee of 100 (2005). The Committee of 100 's Asian Pacific Americans in Higher Education Report Card. New York: Committee of 100.

Cooper, C. (2009). Performing Cultural Work in Demographically Changing Schools: Implications for Expanding Transformative Leadership Frameworks. Educational Administration Quarterly, 45(5), 694-724.

Currie, D.H. (1994). A comparison of leadership styles and perceptions of four leadership constructs held by senior community college administrators differentiated by 
ethnicity/race and gender (Doctoral dissertation, University of Southern California, 1995). Dissertation Abstracts International, 56, 772.

Dantley, M. (2003). Principled, pragmatic, and purposive leadership: Reimagining educational leadership through prophetic spirituality. Journal of School Leadership, 13(2), 181-198.

Darder, A. (1991). Culture and Power in the Classroom. Westport, CT: Bergin and Garvey.

Delgado, R. (1989). Storytelling for oppositionists and others: a plea for narrative. Michigan Law Review, 87, 2411-2441.

Delgado, R. (1993). On telling stories in school: a reply to Farber and Sherry. Vanderbilt Law Review, 46, 665-676.

Delgado, R. (1995). Critical Race Theory: The Cutting Edge. Philadelphia: Temple University Press.

Dillon, J.F., \& Tanner, G.R. (1995). Dimensions of career burnout among educators. Journalism and Mass Communication Educator, 50(2), 4-13.

Eddy, P. (2004). The impact of presidential cognition on institutional change. Community College Enterprise, 10(1), 63-77.

Elmore, R. (2000). Building a new structure for school leadership. Washington, DC: The Albert Shanker Institute.

Evans, A. E. (2007). Changing faces: Suburban school responses to demographic change. Education and Urban Society, 39(3), 315-348. 
Fanon, F. (1963). The Wretched of the Earth. New York: Grove Press.

Freire, P. (1970). Pedagogy of the Oppressed. New York: Continuum.

Fullan, M. (2001). Leading in a Culture of Change. San Francisco: Jossey-Bass.

Fullan, M. (2003). The Moral Imperative of School Leadership. Thousand Oaks, CA: Corwin.

Gardner, J.W. (1990). On Leadership. New York: Free Press.

Giroux, H.A. (1997). Pedagogy and the Politics of Hope. Boulder, CO: Westview Press.

Giroux, H.A. (2010). Lessons from Paulo Friere. Chronicle of Higher Education, 57(9), B16-B16.

Gramsci, A. (1971). Selections from the Prison Notebooks. London: Lawrence and Wishart.

Greenleaf, R.K. (1977). Servant Leadership. New York: Paulist Press.

Gutierrez, M., Castaneda, C., \& Katsinas, S.G. (2002). Latino leadership in community colleges: Issues and challenges. Community College Journal of Research \& Practice, 26(4), 297-314.

Hall, G., \& Hord, S. (2006). Implementing change: Patterns, principles, and potholes. Boston, MA: Pearson Education.

Huiskamp, G. (2002). Negotiating communities of meaning in theory and practice: Rereading Pedagogy of the Oppressed as direct dialougeic encounter. In J.J. Slater, S.M. Fain, \& C.A. Rossatto (Eds.), The Freireian Legacy: Educating for Social Justice (pp. 73-94). New York: Peter Lang. 
Hull, J.R., \& Keim, M.C. (2007). Nature and status of community college leadership development programs. Community College Journal of Research \& Practice, 31(9), 689-702.

Ideta, L.M. (1996). Asian women leaders of higher education: Tales of self-discovery from the ivory tower (Doctoral dissertation, University of Hawai'i, 1996). Dissertation Abstracts International, 57, 4667.

Kumashiro, K. (1999). Supplementing normalcy and otherness: queer Asian American men reflect on stereotypes, identity, and oppression. International Journal of Qualitative Studies in Education (QSE), 12(5), 491-508.

Ladson-Billings, G., \& Tate, W. (1995). Toward a Critical Race Theory in Education. Teachers College Record, 97(1), 47-68.

Larson, C., \& Ovando, C. (2001). I. Belmont, CA: Wadsworth.

Lave, J., \& Wenger, E. (1991). Situated learning: Legitimate puerperal participation. Cambridge, UK: Cambridge University Press.

Levin, J. (1994, November). Community colleges as organizations of change. Paper presented at the annual meeting of the Association for the Study of Higher Education, Tucson, AZ.

Levin, J. (1998). Making sense of organizational change. New Directions for Community Colleges, 102, 43-54.

Lopez, G. R. (2003). The (racially neutral) politics of education: A critical race theory perspective. Educational Administration Quarterly, 39(1), 68-94. 
Lopez, G. R., Gonzalez, M. L., \& Fierro, E. (2006). Educational leadership along the U.S.-Mexico border: Crossing borders/embracing hybridity/building bridges. In C. Marshall \& M. Oliva (Eds.), Leadership for social justice: Making revolutions in education (pp. 64-84). Boston: Pearson Education.

Marshall, C., \& Oliva, M. (Eds.). (2006). Building the capacities of social justice leaders. In C. Marshall \& M. Oliva (Eds.), Leadership for social justice: Making revolutions in education (pp. 1-15). Boston: Pearson Education.

Memmi, A. (1965). The Colonizer and the Colonized. Boston, MA: Beacon Press.

Memmi, A. (2006). Decolonization and the Decolonized. Minneapolis, MN: University of Minnesota Press.

McLaren, P. (1997). Revolutionary Multiculturalism: Pedagogies of Dissent for the New Millennium. Boulder, CO: Westview.

McLaren, P. (2000). Che Guevara, Paulo Freire, and the pedagogy of revolution. Lanham, MD: Rowman and Littlefield.

Mickles, M.B. (2005). A three state study of the experiences and perceptions of African American community college presidents (Doctoral dissertation, University of Virginia, 2005). Dissertation Abstracts International, 66, 872.

Murillo, E. G., Jr. (2002). How does it feel to be a problem? "Disciplining" the transnational subject in the American South. In S. Wortham, E. G. Murillo Jr., \& E. T. Hamann (Eds.), Education in the new Latino diaspora: Policy and the politics of identity (pp. 215-239). Westport, CT: Ablex. 
Neilson, P., \& Suyemoto, K. (2009). Using culturally sensitive frameworks to study Asian American leaders in higher education. New Directions for Institutional Research, 2009(142), 83-93.

Ngugi wa Thiong'o (1986). Decolonising the Mind: The Politics of Language in African Literature. Portsmouth, NH: Heinemann.

Ong, P. (2008) Trajectory of Civic and Political Engagement: A Public Policy Report. Los Angeles: LEAP Asian Pacific American Public Policy Institute.

Parker, L., Deyhle, D., and Villenas, S. (1999). Race Is, Race Isn't: Critical Race Theory and Qualitative Studies in Education. Boulder, CO: Westview Press.

Purpel, D.E. (2004). Reflections on Moral and Spiritual Crisis in Education. New York: Peter Lang.

Quantz, R., Rogers, J., \& Dantley, M. (1991). Rethinking transformative leadership: Toward democratic reform of schools. Journal of Education, 173(3), 96-118.

Rhoads, R., Valadez, J.R. (1996). Democracy, multiculturalism, and the community college: A critical perspective. New York: Garland Publishing.

Riehl, C. J. (2000). The principal's role in creating inclusive schools for diverse students: A review of normative, empirical, and critical literature on the practice of educational administration. Review of Educational Research, 70(1), 55-81.

Senge, P.M. (1990). The Fifth Discipline. New York: Doubleday.

Sergiovanni, T.J. (1992). Moral Leadership. San Francisco: Jossey-Bass. 
Shields, C.M. (2000). Learning from difference: Considerations for schools as communities. Curriculum Inquiry, 30(3), 275-294.

Shields, C.M. (2003). Good intentions are not enough: Transformative leadership for communities of difference. Lanham, MD: Scarecrow.

Shields, C. M., \& Sayani, A. (2005). Leading in the midst of diversity: The challenge of our times. In F. W. English (Ed.), The Sage handbook of educational leadership: Advances in theory, research, and practice (pp. 380-406). Thousand Oaks, CA: Sage.

Shor, I. (1992). Empowering education: Critical teaching for social change. Portsmouth, NH: Heinemann.

Smith, L.T. (1999). Decolonizing Methodologies: Research and Indigenous Peoples. New York: Zed Books Ltd.

Smith-Maddox, R,. \& Solorzano, D. (2002). Using Critical Race Theory, Paulo Freire's Problem Posing Method, and Case Study Research to Confront Race and Racism in Education. Qualitative Inquiry, 8(1), 66-84.

Solorzano, D. (1998). Critical Race Theory, Race and Gender Microaggressions, and the Experience of Chicana and Chicano Scholars. International Journal of Qualitative Studies in Education, 11(1), 121-136.

Solorzano, D.G., \& Yosso, T.J. (2001). Critical race and LatCrit theory and method: counter-storytelling. Qualitative Studies in Education, 14(4), 471-495. 
Strobel, L.M. (2001). Coming Full Circle: The Process of Decolonization Among Post1965 Filipino Americans. Quezon City, PH: Giraffe Books.

Tejeda, C., Espinoza, M., \& Gutierrez, K. (2003). Toward a decolonizing pedagogy: social justice reconsidered. In P.P. Trifonas (Ed.), Pedagogies of Difference: Rethinking Education for Social Change. New York: RoutledgeFalmer.

Teranishi, R., Behringer, L., Grey, E., \& Parker, T. (2009). Critical race theory and research on Asian Americans and Pacific Islanders in higher education. New Directions for Institutional Research, 2009(142), 57-68.

Theoharis, G. (2007). Navigating rough waters: A synthesis of the countervailing pressures against leading for social justice. Journal of School Leadership, 17(1), $4-27$.

Turner, C. (2007). Pathways to the presidency: Biographical sketches of women of color firsts. Harvard Educational Review, 77(1), 1-38.

Valenzuela, A. (1999). Subtractive schooling: U.S.-Mexican youth and the politics of caring. Albany, NY: State University of New York Press.

Vaughan, G.B., \& Weisman, I.M. (1998). The community college presidency at the millennium. Washington, DC: Community College Press.

Villenas, S. (2002). Reinventing educacíon in new Latino communities: Pedagogies of change and continuity in North Carolina. In S. Wortham, E. G. Murillo Jr., \& E. T. Hamann (Eds.), Education in the new Latino diaspora: Policy and the politics of identity (pp. 17-35). Westport, CT: Ablex. 
Weiner, E.J. (2003). Secretary Paulo Freire and the Democratization of Power: Toward a theory of transformative leadership. Educational Philosophy and Theory, 35(1), 89-106.

Wilkinson, J. (2008). Good intentions are not enough: a critical examination of diversity and educational leadership scholarship. Journal of Educational Administration \& History, 40(2), 101-112.

Wong, K. (2007). Emotional labor of diversity work: Women of color faculty in predominantly White institutions. Ph.D. dissertation, Arizona State University, United States - Arizona. (Publication No. AAT 3288033).

Yukl, G. (1999). An evaluation of conceptual weaknesses in transformational and charismatic leadership theories. Leadership Quarterly, 10, 285-305.

Zhou, M. (2003). Urban education: Challenges in educating culturally diverse children. Teachers College Record, 105(2), 208-225. 


\section{APPENDICES}

\section{Appendix A. Semi-Structured Interview Protocol}

1) Please provide your name, current position, and how long you have held your current position.

2) Please describe your leadership career and the previous positions that you have held prior to your current position.

3) Looking back on your leadership career, what experiences or professional development opportunities prepared you for your leadership roles?

4) How do you feel your cultural/ethnic identity impacts your role as a community college administrator?

5) How have these experiences shaped the way you view your leadership identity and leadership style?

6) Can you provide some examples or stories from your own experience which could be used to more adequately reflect the leadership experiences of marginalized communities and people of color.

7) Given these experiences, what do you think would be important for leadership preparation programs to address in order to develop/support administrators of color. 


\title{
Appendix B. Informed Consent Form
}

\author{
San Francisco State University \\ Informed Consent to Participate in a Research Study \\ "Leadership Experiences of Community College Administrators of Color"
}

\section{A. PURPOSE AND BACKGROUND}

The purpose of this research study is to study the leadership experiences of community college administrators of color.

The researcher, Alexis S. Montevirgen, is a graduate student at San Francisco State University conducting research for a doctoral dissertation.

You are being asked to participate in this study because you are an administrator of color holding a leadership position at a community college.

\section{B. PROCEDURES}

If you agree to participate in this research study, the following will occur:

- you will be interviewed for approximately one hour about your leadership experience as a community college administrator of color.

- the interview will be audiotaped to ensure accuracy in reporting your statements.

- the interview will take place at a time and location convenient to you.

- the researcher may contact you later for a follow up interview to clarify your original interview answers for approximately forty-five minutes.

\section{RISKS}

- total time commitment will be approximately two hours.

Participation in the study involves minimal risk. There is a risk of loss of privacy. However, no real names or identities of individual participants or their affiliated colleges will be used in any published reports of the research, pseudonyms will be used for both individual participants and their affiliated colleges. Only the researcher will have access to the research data. There is a risk of discomfort or anxiety due to the nature of the questions asked; however, the participant can answer only those questions he/she chooses to answer, and can stop participation in the research at any time.

\section{CONFIDENTIALITY}

The research data will be kept in a secure location and the researcher's password protected personal computer, and only the researcher will have access to the data. At the conclusion of the study, all identifying information will be removed and the data will be kept in a locked cabinet or office. Audiotapes will be destroyed at the end of the study. 


\section{E. DIRECT BENEFITS}

There will be no direct benefits to the participant.

\section{F. COSTS}

There will be no cost to you for participating in this research.

\section{G. COMPENSATION}

There will be no compensation for participating in this research.

\section{H. ALTERNATIVES}

The alternative is not to participate in the research.

\section{QUESTIONS}

You have spoken with the researcher about this study and have had your questions answered. If you have any further questions about the study, you may contact the researcher by email at amontevi@sfsu.edu or you may contact the researcher's advisor, Associate Professor Allyson Tintiangco-Cubales at aticu@sfsu.edu. Questions about your rights as a study participant, or comments or complaints about the study, may also be addressed to the Office for the Protection of Human Subjects at(415)338-1093 or protocol@sfsu.edu.

J. CONSENT

You have been given a copy of this consent form to keep.

PARTICIPATION IN THIS RESEARCH IS VOLUNTARY. You are free to decline to participate in this research study, or to withdraw your participation at any point, without penalty. Your decision whether or not to participate in this research study will have no influence on your present or future status at San Francisco State University.

Signature

Date:

$$
\text { Research Participant }
$$

Signature

Date: 